\title{
Obrando la defensa: los mundos laborales de la construcción y de la maestranza. San Carlos de Perote-Veracruz (Nueva España), 1770-1788
}

Eder Gallegos Ruíz*

Recibido: marzo de 2014 Aprobado: julio de 2014

Resumen: Este artículo analiza el mundo laboral de dos "posiciones estratégicas" en tiempos de zozobra: los constructores de la fortaleza de San Carlos y los operarios de su fábrica de armamentos, detallando la necesidad de una adecuada cadena de abastecimiento, así como sus particulares regímenes laborales. En sus diferenciaciones (de ser llamados peones pasan a ser obreros junto a operarios) radica el quiebre entre la labor no calificada en "Antiguo Régimen" y actividades tentativamente proto-industriales. Tanto los trabajadores imbuidos en la construcción como los operarios de la maestranza fueron actores sociales de primer orden y su labor resultó clave pues de ellos dependió, en cierta medida, la defensa del sistema económico de la monarquía y la sobrevivencia del régimen novohispano.

Palabras clave: Nueva España, arte de la guerra, equipamiento militar, defensa militar, labor, fortificación.

* Magister en Historia, Universidad Pablo de Olavide, España. Cursa estudios doctorales en Historia en El Colegio de México.goseder@gmail.com

\footnotetext{
$\sqrt{\overline{\sqrt{\sqrt{10}}}}$

EL TALLER DE LA HISTORIA, vol. 6, n. ${ }^{\circ}$ 6, 2014, págs. 175 - 216. Issn: 1657-3633; e-Issn: 2382-4794. Programa de Historia, Facultad de Ciencias Humanas, Universidad de Cartagena de Indias, Colombia
} 


\section{Acting defense: The construction work and Maestranza in San Carlos de Perote-Veracruz (Nueva España), 1770-1788}

Abstract: This paper analyzes the labor market two "strategic positions" in times of distress: the builders of the fortress of San Carlos and operators of their armaments factory, detailing the need for adequate supply chain, and their particular labor regimes. In their differentiations (to be called pawns become workers with workers) lies the break between unskilled work in "Antiguo Régimen" and tentatively proto-industrial activities. Both workers imbued with the construction and the workers of the arsenal were social actors of the first order and its work was key for theirs depended to some extent, the defense of the economic system of the monarchy and the survival of the regime novohispano.

Key words: New Spain, warfare, military equipment, military defense, arms race, traditional technology.

\section{Entre libres y forzados: Los constructores de la fortaleza}

En la conformación misma del virreinato de la Nueva España se encuentra el reto de cómo defender un territorio tan vasto y con tan intrincada geografía, pues ante las estrepitosas caídas de Manila y la Habana de 1762, la administración Borbónica necesitó urgentemente crear una defensa funcional basada en una exitosa centralización fiscal para sostener tropas y erigir fortificaciones. ${ }^{1}$ La lucha oceánica había convertido a las principales posesiones españolas de América en la discordia del resto de las monarquías, integrándolas como un factor en la balanza del poder europeo. $^{2}$

\footnotetext{
1 Según Luz Marina Arias hubo un cambio estructural a partir de la guerra de los siete años en la materia constructiva de fortificaciones gracias a una exitosa centralización fiscal en Nueva España. Entre 1760 y 1790 la tasa de crecimiento de los ingresos fiscales en el México colonial fue uno de las más altas del mundo lo que le permitió reforzar las defensas militares. Luz Maria Arias, "Building Fiscal Capacity in Colonial Mexico: From Fragmentation to Centralization", in The Journal of Economic History n. ${ }^{\circ}$, Cambridge, Cambridge University Press, 2013, pp.662, 674.
}

2 María De la Fuente, El arte militar en la Nueva España, 1762-18o8, México D. F., tesis para obtener el grado de Doctor en Historia, UNAM, 2005, p.48 
Imagen 1

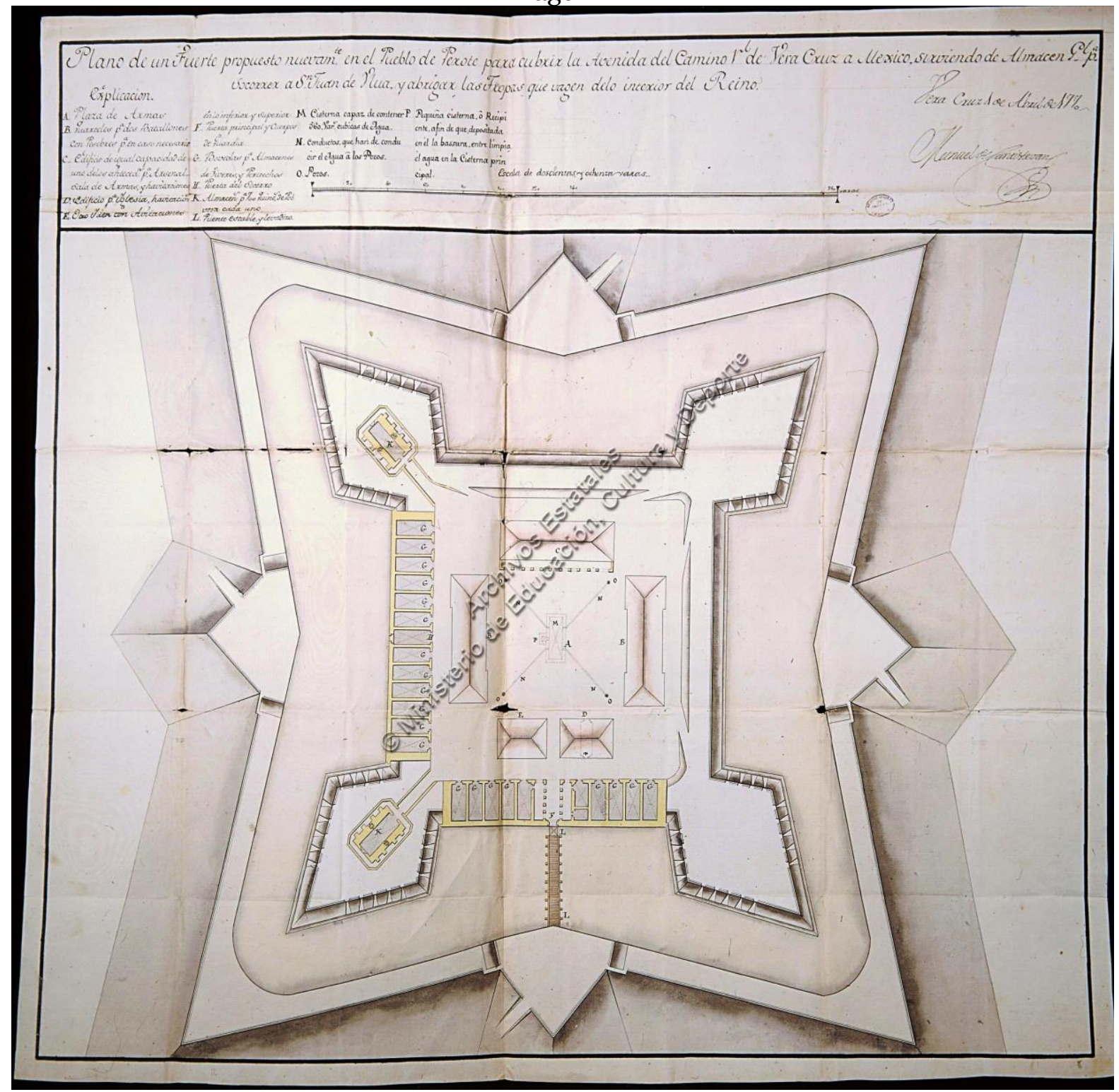

Fuente: "Plano de un Fuerte propuesto nuevamente en el Pueblo de Perote para cubrir la Avenida del Camino Real de Vera Cruz á México, sirviendo de Almacen General para socorrer á San Juan de Ulúa y abrigar las tropas que vengan de lo interior del Reino”, en Archivo General de Indias, Mapas y Planos-México, 254 


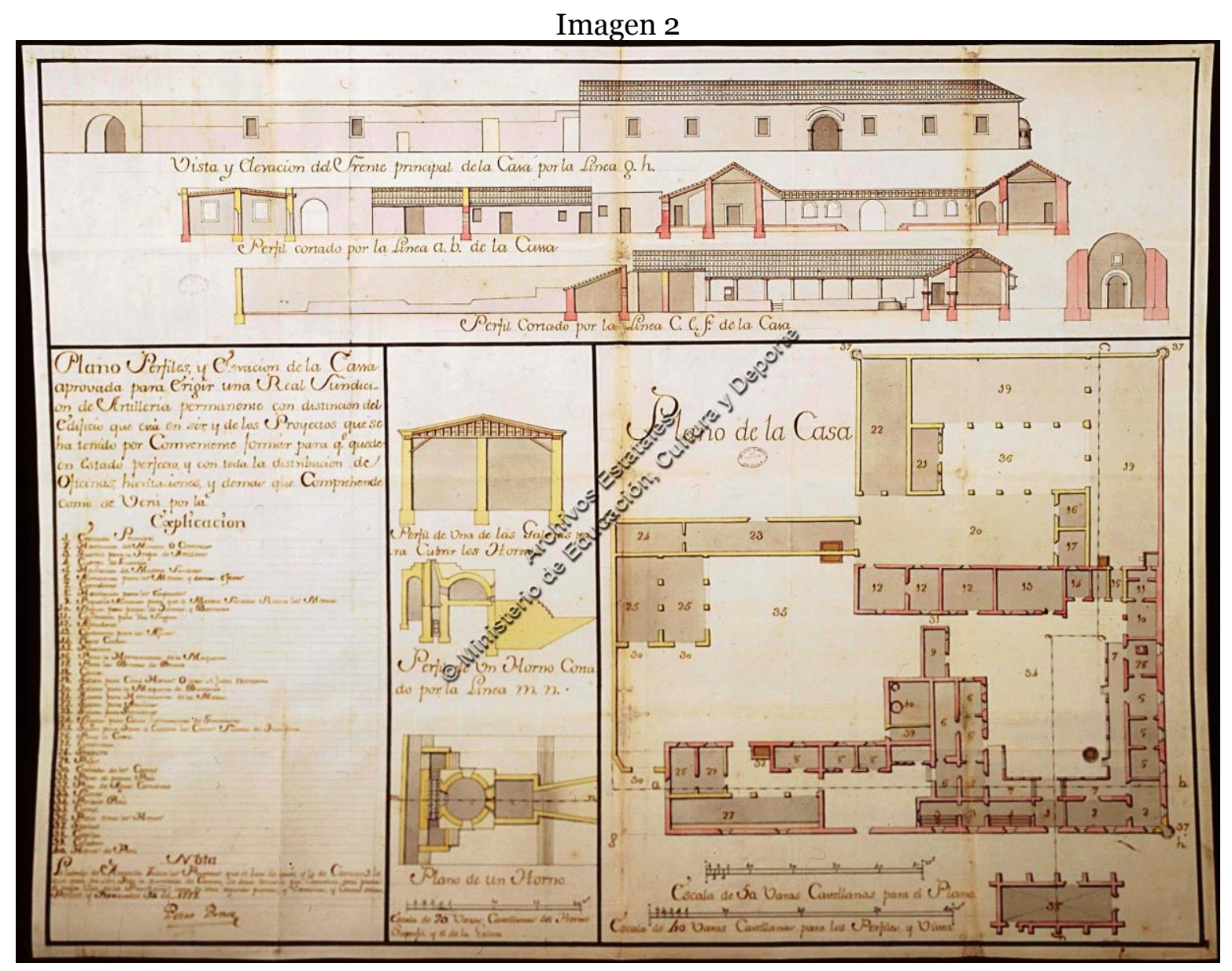

Fuente: "Plano, perfiles y elevación de la Casa aprovada para erigir una Real Fundicion de Artilleria permanente con distincion del edificio que está en ser y de los Proyectos que se ha tenido por conveniente formar para que quede en estado perfecto y con toda la distribución de oficinas, havitaciones y demás que comprehende como se verá por la explicación”. Archivo General de Indias, Mapas y Planos-México, 336.

\section{La reciente importancia de Nueva España dentro de este orden incrementa-} ba las posibilidades de peligro, no solo de un saqueo corsario, ${ }^{3}$ sino de una invasión

3 Aunque desde la segunda mitad del siglo XVII el peligro rondó frecuentemente al Virreinato con ataques piratas a Campeche en 1678, a Tampico en 1682 y a Veracruz en 1683. Las estrepitosas caídas mencionadas, así como la perdida de Florida tras el tratado de Paris en 1763, revivieron los proyectos de crear eficientes defensas fortificadas, así como dotar de artillería a zonas estratégicas hasta entonces olvidadas. Christon Archer, "The role of the Military in Colonial Latin America", in The History Teacher n. $^{\circ}$ 3, California, The Society for History Education, Inc., 1981, pp.413-421; El ejército en el México Borbónico: 1760-1810, México D. F., FCE, 1983. 
terrestre que utilizaría las posiciones pérdidas por la corona ante los ingleses a modo de trampolines hacia el corazón del territorio, por lo que controlar el camino real sería objetivo prioritario. En estas circunstancias se diseñó el proyecto de erigir una fortaleza en un punto estratégico entre el puerto de Veracruz y la ciudad de México, siendo escogida tras un largo proceso de deliberación la villa de San Miguel de Perote, ${ }^{4}$ constituida para entonces por 150 familias de españoles, mestizos e indios, ${ }^{5}$ la que contaba con clima favorable para la conservación de víveres ${ }^{6}$ y en sus alrededores había una importante producción agropecuaria en cinco haciendas de labor y once ranchos, además de pastos abundantes donde había ganado mayor y menor. ${ }^{7}$

Lo anterior justificaba el definitivo proyecto constructivo del ingeniero Manuel de Santisteban en $1770 .{ }^{8}$ El plan de erigir la fortaleza de San Carlos estaba finalmente aprobado, pero lo que la historiografía hasta ahora no ha profundizado es ¿Cómo y quién la construyó? ¿Fueron solo forzados? ¿Cómo se solventarían los retos logísticos? Como primer acto, las herramientas de labor necesarias para la obra se pidieron a la plaza de Veracruz y el virrey sugirió también la posibilidad de enviar a Perote el hierro y el acero suficientes para su construcción. ${ }^{9}$ Los instrumentales llevados de Veracruz a Perote el 4 de abril de 1770 constaron, entre otros, de 2000 picos, 200 paletas y palanquetas, 2000 palas, 2000 azadas y 100 hachas

4 El proyecto fue propuesto desde 1760 por el virrey Cruillas como un arsenal. David Ramírez, Testimonio para una Historia de Perote, Xalapa, Editorial del Gobierno del Estado de Veracruz, 1973, p.40; En 1766 el Marques de Croix propondría que se fortificara la zona de Perote, comenzando una álgida controversia con el Conde de Aranda que finalmente ganaría. José Antonio Calderón, Historia de las fortificaciones en Nueva España, Madrid EEHA/CISC/Gobierno del Estado de Veracruz, 1984, pp.182-187.

5 Peter Gerhard, Geografía histórica de la Nueva España. 1519-1821, México D. F., Instituto de Investigaciones Históricas, Universidad Nacional Autónoma de México, 1986, p.387.

6 Miguel Sanchez, El castillo de San Carlos de Perote, México D. F., Ed. Citlaltepetl, 1971, p.19.

7 Estas se encontraban en funciones desde 1746. D. Ramírez, Testimonios para una historia de Perote, p.43.

8 El virrey marqués de Croix, propuso la erección final del fuerte de Perote para proteger el camino de Xalapa, idea que finalmente fue aprobada en 1770. San Carlos, proyectado por Santisteban, sería uno de los fuertes regulares más interesantes desde el punto de vista del diseño. Ramón Gutiérrez, Fortificaciones en Iberoamérica, Madrid, Fundación Iberdrola/Ediciones El Viso, 2005, p.86

9 Sara Elizabeth Sanz, Fortalezas históricas de Veracruz, México D. F., Secretaría de Educación/ Gobierno del Estado de Vearcruz/Llave, 2010, p.154.

Dossier: Artesanos: formas de trabajo, sociabilidades, movilidad social y cultura política en Hispanoamérica, siglos XVI-XX 
como se detalla en la tabla 1 adjunta en el anexo al final del artículo. ${ }^{10}$ Todas fueron entregadas a un maestro carpintero con 6 oficiales y un maestro herrero con 4 oficiales para su revisión, señalando Manuel de Santisteban que toda herramienta que llegase a faltar en los reales almacenes se haría en la misma obra, llevando el hierro suficiente de Veracruz. Lo mismo sucedió con el ladrillo que comenzó a ser fabricado en el sitio. ${ }^{11}$

Sobre el transporte de materiales como piedra, cantería y arena se solicitó al pueblo de Chalchicomula 600 mulas y 60 carretas, ${ }^{12}$ realizándose dos o tres viajes al día y en ocasiones hasta cuatro. ${ }^{13}$ Los costos de operación del transporte alcanzaron los 6.600 pesos hacia mayo de 1770 como se detalla en las tablas 2 y 3 (ver anexos). En estas notas de los gastos generales del transporte de cal y piedra se detalla que las mulas necesitaban tres descansos al día, y que éstas requerían además un gasto en alimentarlas con paja, el salario de un mozo para mantenimiento de los carretones y asegurar al abastecimiento de bestias de carga en caso de remplazo. Además, señala la necesidad de errarlos porque sin ello no podían subsistir largos trayectos. Obviamente mencionaba que a mayor distancia era mayor el costo de flete y que durante las fiestas populares los arrieros no trabajaban. ${ }^{14}$

Santisteban envió carta al Virrey Carlos Francisco de Croix para solicitarle abasto de cal, éste a su vez la solicitó a Thomas Moreno, alcalde de San Juan de los Llanos, pues en la zona era abundante y a precios más bajos. Thomas Moreno informó al virrey que envió la cantidad de ciento cincuenta mil arrobas de cal y ciento veinticinco mil de piedra; los materiales tuvieron el coste de diecisiete mil pesos, que fueron los más bajos en relación a los costos de abastecimiento vía el poblado de Perote. ${ }^{15}$

10 AGN, Reales Cedulas Originales y duplicados, exp.77, f.3.

11 AGN, Reales Cedulas, Originales y duplicados, exp.77, f.6.

12 Por otra parte, de las haciendas Jesuitas que existían en el Camino Real fueron sacadas algunas mulas y carretas. AGN, Reales Cedulas, Originales y duplicados, exp.77, f.27.

13 AGN, Reales Cedulas, Originales y duplicados, exp.77, f.29.

14 AGN, Reales Cedulas, Originales y duplicados, exp.77, f.85v.

15 AGN, Reales Cedulas, Originales y duplicados, exp.77, f.84. 
Estos insumos e instrumentos fueron utilizados en la primera etapa constructiva ${ }^{16}$ por trabajadores forzados, que se utilizaban en las obras públicas de entonces. ${ }^{17}$ Los primeros 100 que llegaron construyeron sus propios barrancones y los del resto por llegar. Esta primera oleada probablemente arribó de las cercanías en calidad de "vagos"18 pero también es probable que fueran presidiarios de regiones lejanas. ${ }^{19}$ Aunado a lo anterior, el 15 de junio de 1770 el tesorero Thomas de Rajadel informó que contaba en sus manos con 10 mil pesos para la construcción de galeras en las que se alojarían a los trabajadores, empezando el acopio de los materiales; primeramente sacaron la madera seguida del acarreo de la piedra y su pulverización. Cabe mencionar que esta actividad era tan indeseable que cuando era descubierto algún trabajador "vagabundo" se le asignaba a modo de castigo. ${ }^{20}$ Las galeras debían estar listas en dos meses, mientras que construían dos casetas provisionales de tierra y madera para alojar al ingeniero en jefe. ${ }^{21}$

El suministro alimenticio para los forzados nunca pudo faltar, pero ante la inestabilidad del precio de los granos por la aplicación de la Real pragmática de

16 Durante el primer año se realizó un foso y los cimientos de la fortificación, luego los muros "de cortina”, así mismos los baluartes se fueron levantando hasta una altura de 1,20 metros aproximadamente y dividiendo la figura de la fortificación con una línea diagonal en dos secciones. Durante los primeros seis meses del año, se construyeron los muros de la primera sección. S. E. Sanz, Fortalezas historicas de Veracruz, pp.154-156.

17 Silvio Zavala, El servicio personal de los indios en la Nueva España, t.vII, Mexico D. F., El Colegio de México/El Colegio Nacional, 1995, pp.757-760

18 Para las obras de reparos de la fortificación de San Juan de Ulúa que se iniciaron seis años después fueron "cogidos de leva" sesenta individuos en Veracruz, no teniendo "otro objeto que el del bien público y el exterminio de gente vaga”. Silvio Zavala, Fuentes para la Historia del trabajo en la Nueva España, vol.viII, México D. F., Centro de Estudios Historicos del Movimiento Obrero Méxicano, 1980, pp.288-289.

19 S. E. Sanz, Fortalezas historicas de Veracruz, p.154; En la documentación consulatda no se hace refrencia a esta primera oleada. Silvio Zavala nos da indicios de que probablemente pudieron ser presos de guerra provenientes de las provincias internas. Por otra parte, un ejemplo de la movilidad de los servivios forzados fue el caso de un preso mulato llamado Marcelino que de Cohauila terminó bajo las ordenes del comandante de la fortaleza de San Carlos el mismo año que iniciaron las obras. Silvio Zavala, Los esclavos indios en Nueva España, México D. F., El Colegio Nacional, 1994, pp.353-354.

20 AGN, Reales Cedulas, Originales y duplicados, exp.77, f.34v.

21 AGN, Reales Cedulas, Originales y duplicados, exp.77, f.38v.

Dossier: Artesanos: formas de trabajo, sociabilidades, movilidad social y cultura política en Hispanoamérica, siglos XVI-XX 
1765 en centros tradicionales de abasto como Puebla, ${ }^{22}$ se buscó un arreglo de precios más bajos con Xalapa, ${ }^{23}$ además buscaron en la misma Villa de San Miguel de Perote bajos costes en comestibles y materiales de primera necesidad para el fuerte, siendo el tesorero quien tuvo el cargo de conseguir semanalmente la "ministra". ${ }^{24}$

Con el resguardo de las herramientas y el hospedaje en curso el 9 de mayo de 1770 Santisteban solicitó al virrey de 400 a 500 peones más para la construcción del fuerte. ${ }^{25}$ Aunque en un primer momento se requirió de forzados, pronto prefirió cambiar de régimen laboral. En las inmediaciones del pueblo de Perote se encontraron suficiente personal dispuesto a laborar como peones libres ${ }^{26}$ asignándoseles para ello un salario de 2 reales diarios (un sueldo promedio). Se hacía este tipo de pago por día puesto que se temía que fueran proclives a la huida. Sobre todo para volver a sus redituables labores agrícolas.

Por su parte, el personal forzado que fue solicitado llegó de lugares como Xalapa, Teziutlán y San Juan de los Llanos. ${ }^{27}$ Además, al gobernador de Puebla le fueron solicitados canteros y albañiles libres; dichos individuos fueron advertidos previamente de la obligación que tendrían al estar en las estratégicas obras de Perote. ${ }^{28}$

22 Véase Amilcar Challú, "Grain markets, free trade and the Bourbon reforms: The Real Pragmática of 1765 in New Spain”, in Colonial Latin American Review n. ${ }^{\circ}$, Austin, Texas University Press, 2013 , p.408.

23 AGN, Reales Cedulas, Originales y duplicados, exp.77, f.87v.

24 Ministras hace referencia a todo abasto alimenticio. AGN. Registros de finanzas, caja 4885, exp.63, f.8v.

25 AGN, Reales Cedulas, Originales y duplicados, exp.77, f.25.

26 En el expediente consultado en el fondo "Reales Cedulas" se refiere a los constructores en genérico como peones. Según la primera acepción del Diccionario de la Real Academia de la Lengua Española editado en 1780 , peón es "el que en las obras mercenarias trabaja por su jornal, o en cosas materiales, que no piden arte, ni habilidad". http://goo.gl/kVJ4nI (Consulta: 22 de mayo de 2014). En el expediente consultado dentro del fondo "Indiferente de guerra" son constantemente llamados "obreros" y "operarios". El primer término de una forma general a todos los trabajadores de la fábrica de armamentos mientras que "operario" se utiliza para los trabajadores más cercanos a la labor técnica especializada, aunque lo hacen en ocasiones de forma indistinta. AGN, Indiferente de Guerra, vol.276a, 35fs; Según el Diccionario de la Real Academia de la Lengua Española editado en 1780, operario es "el que obra y trabaja en alguna cosa" mientras que la primera acepción de obrero es "el oficial que trabaja por jornal en las obras de las casas, y en las labores del campo". http://goo.gl/7UTkKY (Consulta: 22 de mayo de 2014).

27 AGN, Reales Cedulas, Originales y duplicados, exp.77, f.27.

28 AGN, Registros de finanzas, caja 4885, exp.63, f.263.; AGN, Reales Cedulas, Originales y duplicados, exp.77, f.266. 
Quizás por la gradual confianza en la estadía de los primeros trabajadores libres es que Santisteban le pide en una carta al virrey que fueran utilizados jornaleros con salario mensual de 8 a 12 pesos. ${ }^{29}$ Como podemos observar, las labores que se llevaron a cabo en Perote no solo tuvieron un impacto en la población próxima sino a nivel regional e inter-regional al transportar material pues hubo escases de cantera que ya no se encontró en Veracruz y se tuvo que traer de Campeche ${ }^{30}$. Además se tuvo que solicitar constantemente mano de obra lo que incentivó la migración de peones libres por estaciones.

Las comunidades cercanas de Altotonga y Teziutlán vieron disparadas su oferta laboral, el día 25 de junio de 1770 se había solicitado que se extrajera piedra de una cantera a una lengua de distancia ${ }^{31}$ y sus pobladores frecuentemente suministraban la madera para los barracones. ${ }^{32}$ A fines de 1770 , coincidiendo con la llegada del ingeniero Miguel del Corral a la obra, todas las galeras para el alojamiento habían sido concluidas y se comenzaron a ocupar por los nuevos indios libres que llegaron por el trabajo de excavación del foso seco. Los vecinos del pueblo de Perote prestaron sus caballos para la conducción del material que estaba estipulado por un quintal y la excavación del foso se ejecutó con 350 de estos "naturales". 33

El 17 de marzo de 1772 se habían fabricado al horno 6.50o ladrillos; ${ }^{34}$ el 5 de junio del mismo año 1772 otros 4.800 ladrillos; 35 para el 12 de junio se fabricaron 5.600 más ${ }^{36}$ y el 26 de junio de 1772 se fabricaron 4.500. ${ }^{37}$ Como se aprecia, la producción fue proverbial, pues no pasaba más de un mes para hacer un alto porcentaje de este material para la realización del proyecto.

29 AGN, Reales Cedulas, Originales y duplicados, exp.77, f.30.

30 AGN, Reales Cedulas, Originales y duplicados, exp.77, f.250.

31 AGN, Reales Cedulas, Originales y duplicados, exp.77, f.38v.

32 Esto lo sabemos gracias que comunicaron a los oficiales de Veracruz que el material fue almacenado en las galeras del tesorero real Thomas de Raja del AGN, Reales Cedulas, Originales y duplicados, exp.77, f.51.

33 AGN, Reales Cedulas, Originales y duplicados, exp.77, f.72v.

34 AGN, Reales Cedulas, Originales y duplicados, exp.77, f.190

35 AGN, Reales Cedulas, Originales y duplicados, exp.77, f.273.

36 AGN, Reales Cedulas, Originales y duplicados, exp.77, f.277.

37 AGN, Reales Cedulas, Originales y duplicados, exp.77, f.281.

Dossier: Artesanos: formas de trabajo, sociabilidades, movilidad social y cultura política en Hispanoamérica, siglos XVI-XX 
Para el 22 de mayo de 1772, trabajaban cincuenta albañiles, trescientos treinta peones, doce canteros, un maestro mayor, un sobrestante mayor y diez capataces; con un número similar de peones forzados. Los detalles de sus nombres, cargos específicos y sus sueldos se han detallado en las tablas 4 a 9. Los ingenieros proyectaron que con esta cantidad de materiales y de peones terminarían los edificios interiores en un año y cuatro meses, y toda la obra en tres años y nueve meses. ${ }^{38}$

Pero si nos atenemos a estas descripciones solamente parecería que los peones fueron solo máquinas de trabajo continuo, más los factores sociales y culturales propios de la sociedad novohispana tuvieron su impronta en el mundo laboral de San Carlos. Fue constante el discurso de las autoridades españolas de entonces acerca de la naturaleza del indio a detener la labor por su propensión al alcoholismo, ${ }^{39}$ esto fue un argumento contante para quienes preferían el trabajo forzado sobre el libre a jornal. ${ }^{40}$ En San Carlos los episodios en que las autoridades tuvieron que intervenir fueron reales: Un ejemplo lo consta cuando el 27 de marzo de 1770, los trabajadores del fuerte junto con los moradores del pueblo de Perote, utilizaron bebidas prohibidas y "zumos no permitidos", a cuyo remedio intervino la justicia del lugar. ${ }^{41}$

Durante la construcción del fuerte de San Carlos también intervinieron factores religiosos. Durante la semana santa y pascua, los peones libres se retiraron a sus casas. Sobrando una mínima de peones forzados, de los cuales no pudieron ha-

38 AGN, Reales Cedulas, Originales y duplicados, exp.77, f.264v.

39 Según Solange Alberro las autoridades asumieron constantemente actitudes contradictorias que reflejaban una realidad de hecho inevitable. Los censores religiosos especialmente denunciaron sin cesar los estragos causados por el alcoholismo sobre la población en general y solicitaron que la Corona prohibiera o al menos limitara la producción local de pulques o alcoholes destilados, favoreciendo el monopolio peninsular deseoso de vender en tierras americanas. Solange Alberro, "Bebidas alcohólicas y sociedad colonial en México: un intento de interpretación”, en Revista Mexicana de Sociología n. ${ }^{\circ}$ 2, México D. F., El Colegio de México, 1989, p.357

40 Por ejemplo, en la misma época se estaba llevando a cabo similar discusión entre los que preferían el trabajo forzado y los que defendían el libre en el virreinato del Perú. En la mina de Azogue de Huancavelica, otro mundo del trabajo estratégico, las autoridades esgrimían que el alcoholismo era parte de la naturaleza de los indígenas por lo que solo forzándolos podrían laborar correctamente. Juan Francisco Marroquin director de la mina apuntó "no poder remediar las borracheras que los Indios tienen por este tiempo [...]. Este bicio nunca se les a podido quitar por mas diligencias que se han hecho Archivo General de Indias (AGI), Lima, 1330. Oficio de Juan Francisco Marroquín a Fernando Márquez de la Plata. Cerro de Santa Bárbara, 4 de mayo de 1785.

41 AGN, Reales Cedulas, Originales y duplicados, exp.77, f.189. 
cer gran parte de la obra. ${ }^{42}$ Se puede afirmar que el catolicismo impuso los ritmos laborales en San Carlos. Todos los días del año se detenían las obras durante una hora para celebrar misa a la que todos asistan. También todo aquel que no fuera indígena estuvo obligado a asistir al rito, pues consideraban que "en nada le perjudicaba el no trabajar por una hora". Sirviendo la ceremonia religiosa a modo de descanso de las grandes fatigas. ${ }^{43}$

El tesorero pagador fue el encargado de la administración de la tesorería, fue el trabajador que manejó los negocios durante la obra, siempre tuvo que hacer tratos con los materiales y los trabajadores para que no le perjudicara demora o retraso alguno durante la construcción, su horario de trabajo fue de las siete y media de la mañana hasta las doce del día y de tres a cinco de la tarde. ${ }^{44} \mathrm{El}$ escribano realizó una lista de los peones con sus nombres y apellidos, en caso de que alguno muriera durante la construcción fuera sustituido por otro trabajador rápidamente para que no hubiera pérdida de tiempo, anotando los nombres de altas y bajas en dicha certificación. ${ }^{45}$

$\mathrm{Al}$ alcalde de la villa de Córdoba Santisteban envió una carta señalando que para los gastos constructivos, era más económico remplazar a los albañiles durante cada mes, porque así evitaron que se enfermaran los obreros y estos se mantuvieran de pie; aprendiendo "el tipo arquitectura militar que ellos laboraron", hubo algunos despidos de trabajadores por inútiles, dichos peones fueron todos remplazados por temporadas. ${ }^{46}$

El tesorero tuvo prohibido pagar a los trabajadores con anticipación o que recibieran algún préstamo, a menos de que tuvieran vencido algún pago, ellos no podían recibir regalos ni dádivas por muy cortas que fueran. No obstante los asun-

42 AGN, Reales Cedulas, Originales y duplicados, exp.77, f.230.

43 AGN, Obras Públicas, exp.24, f.10

44 AGN, Registros de finanzas, depósito y obligaciones, caja 4885, exp.63, ff.5 y $7 \mathrm{v}$.

45 Sin duda es un tema poco explorado y apasionante, por desgracia en el expediente que hasta ahora se ha consultada solo encontré referencia de esta certificación pero no contiene un ejemplo sobre las defunciones de los trabajadores de la fortaleza, hace falta un posterior estudio con más tiempo. AGN, Registros de finanzas, caja 4885, exp.63, f.6v.

46 AGN, Registros de finanzas, depósito y obligaciones, caja 4885, exp.63, f.299.

Dossier: Artesanos: formas de trabajo, sociabilidades, movilidad social y cultura política en Hispanoamérica, siglos XVI-XX 
tos de la real hacienda fueron tratados con jueces y con el tesorero, que debió guardar la mejor armonía y tratar con la mayor "urbanidad y política" ${ }^{47}$

El 27 de junio de 1772 los albañiles de Orizaba, Córdoba, San Andrés Chachicomula y Xalapa se ausentaron sin el debido permiso de la edificación, junto a otros que si contaban con un certificado de autorización temporal por sus diligencias propias en el agro, pero que no regresaron más a Perote. Por la falta de albañiles en la obra se había desarrollado un considerable atraso en un edificio de almacén que se había adelantado hasta entonces con gran rapidez. El ingeniero mandó a prevenir a los alcaldes de los referidos lugares que apremiaran a obligar a los citados peones a volver a las obras de Perote "con apercibimiento" y que los albañiles fueran castigados si no tuvieran en la mano su licencia de retiro temporaria. ${ }^{48} \mathrm{El}$ ingeniero Santisteban no debía por ningún motivo paralizar la obra por lo que, cuando se encontraron con los trabajadores que faltaron a las normas fueron severamente castigados obligándolos a laborar como picapedreros..$^{49}$

Por otra parte, resulta innegable que el entorno donde se laboró afectó el ritmo de la obra. Circunstancias como el estado del tiempo influyó en la construcción, del 5 al 11 de septiembre de 1772 ocurrieron intensas lluvias que fueron causa de que los obreros perdieran algunos días de trabajo, aunque sin que hubiera daño alguno en la obra por el grosor de los muros que resistieron la fuerza del torrente y deslaves. Del 19 al 25 del mismo mes perdieron más días de trabajo por que continuaron las intensas lluvias. 50

Una vez que se pasó la primera etapa constructiva que consistió en el arreglo (chapeo y aplanamiento) del terreno, la excavación del fosos por los "naturales" y la disposición de los cimientos del muralla principal, se procedió al levantamiento de este muro principal hasta una altura de "once varas" y cercando con este muro todo el terreno; luego se hicieron las bóvedas, portones, parapetos con sus troneras y se erigió la contraescarpa. ${ }^{51}$

47 AGN, Registros de finanzas, depósito y obligaciones, caja 4885, exp.63, f.7.

48 AGN, Registros de finanzas, depósito y obligaciones, caja 4885, exp.63, f.297.

49 AGN, Registros de finanzas, depósito y obligaciones, caja 4885, exp.63, f.298.

50 AGN, Registros de finanzas, depósito y obligaciones, caja 4885, exp.63, f.350.

51 Según el Diccionario de la Real Academia de la lengua española de 1780 es "el declive de la parte de muralla, que está dentro del foso”. http://goo.gl/xu2LDw. (Consulta: 23 de mayo de 2014) 
Al dejar el virrey Croix su cargo en 1771, informó a su sucesor Bucareli que la principal finalidad que se lo podría dar a la fortaleza sería la de mantener un cuerpo de tropas y ser centro de acopio de vivires y utensilios, a fin y socorrer en caso de necesidad de ataque; para ello, se dispuso la construcción de dos casamatas en las proximidades de la obran principal para poder almacenar pertrechos y gran cantidad de pólvora pues su clima, que es regularmente seco, facilitaba su conservación. Finalmente, se hicieron los almacenes y se soló (dotó de servicios) al primer piso de la fortaleza hacia 1775, pero quedaron aún muchas partes secundarias que los peones libres y forzados tuvieron que concluir hasta 1777 a un coste general para la Real Hacienda de 659.886 pesos. ${ }^{52}$

De esta forma quedo concluido un baluarte bajo el diseño francés denominado "primer sistema de Vauban" que permitía desde sus múltiples ángulos proyectar su poder de fuego, ${ }^{53}$ pero sus capacidades defensivas nunca fueron puestas a prueba. Varios años después el virrey Mayorga objetó que su ubicación estaba errónea y que su construcción había sido defectuosa desde sus cimientos, lo que sepultó cualquier uso futuro como fortaleza. Sin embargo, abría múltiples opciones para su uso, como un arsenal e incluso como sede de una fábrica de armamentos que para entonces ya comenzaba a operar.

\section{Labor técnica y pureza de sangre: Operarios de la maestranza}

Durante el siglo XVIII la Corona Española se encontraba a la defensiva ante el expansionismo de la monarquía inglesa allende los mares. En los teatros americanos esta necesidad había impulsado proyectos para erigir fortalezas en puntos estratégicos de los virreinatos, como en el caso de San Carlos de Perote. Al abrirse nuevos teatros bélicos se priorizó la disposición militar y la necesidad del uso de tecnología de punta, exigiendo una nueva producción bélica acorde a las condiciones de mo-

52 J. A. Calderón, Historia de las fortificaciones en Nueva España, pp.187-188

53 Francisco Muñoz et Benjamín Blaisot, "L’influence de Vauban en Amérique Latine”, en Thierry Martin et Michèle Virol (coord.), Vauban, architecte de la modernité?, Paris, Presses Universitaires de Franche-Comté, 2008, p.197. 
narquías globales. ${ }^{54}$ Por tanto, ante las nuevas circunstancias ¿De dónde sacar armamento? La respuesta es, de las maestranzas, lugares donde se lleva a cabo una labor con maestría. ${ }^{55}$ Fábricas de artillería y fusiles donde además se almacenaban y reparaban la artes armamentística.

La capacidad productiva de la monarquía española para enfrentar los retos globales estaba lejos de ser adecuada. ${ }^{6}$ Tradicionalmente, el armamento de "las Indias" se producía en la fábrica de artillería del barrio de San Bernardo en Sevilla; ${ }^{57}$ pero conforme los escenarios bélicos se ensanchaban, resultaba cada vez más inviable depender solo de esta, por lo que se proyectó transferir conocimiento técnico a Nueva España. En 1768, se estableció una modesta maestranza de artillería en el puerto de Veracruz gracias al traslado de los técnicos operarios de la fábrica de artillería de Sevilla, 58 "un sargento de carreteros, un obrero, y dos aprendices: un sargento de terrenos, y dos cabos”. Una década después, en 1778, los operarios

54 Christen Jörgensen et al, Técnicas Bélicas del mundo moderno, 1500-1763. Equipamiento, técnicas y tácticas de combate, Madrid, Ed. Libsa, 2007, pp.15-24.

55 El vocablo Maestranza deviene de "Maestrante", es decir aquel que Amaestra, "A" es un prefijo latino que significa "con" más la partícula "maestra", es decir la "Maestranza" es aquel lugar donde se lleva a cabo algo con maestría. Según la Real Academia de la Lengua Española, Maestranza también tiene las siguientes acepciones. 1. Sociedad de caballeros cuyo objeto es ejercitarse en la equitación, y que en su origen fue escuela del manejo de las armas a caballo. 2. Conjunto de los talleres y oficinas donde se construyen y recomponen los montajes para las piezas de artillería, así como los carros y útiles necesarios para su servicio. 3. Conjunto de oficinas y talleres análogos para la artillería y efectos movibles de los buques de guerra. http://goo.gl/CePyOk. (Consulta: 10 de mayo de 2014)

56 La capacidad de producción de España desde el siglo XVI era exigua. Pero el principal problema del desarrollo de la tecnología en general no es solo su inventiva y manufactura, sino la conjunción de estas con una sociedad receptiva y adecuada para su desarrollo. En el caso de España no se cumplían estas últimas premisas a pesar de que no se escaseaba en materiales, sino más bien mano de obra calificada por lo que se invitó a fundidores extranjeros. Pero una vez resueltas las problemáticas inmediatas, se les despedía por cuestiones económicas. Carlo Cipolla, Las Maquinas del tiempo y de la Guerra: Estudio de la génesis del capitalismo, Barcelona, Editorial Crítica, 1999, p.104.

57 Desde 1565 se contrató bajo asiento la fundición particular de bronces de la familia Morel por la Casa de Contratación de Indias y en 1634 la fábrica pasa a ser propiedad de la Real Hacienda y se le nombra "Real Fábrica de Artillería", iniciándose el régimen que se llamaría de los "asentistas", en el que los fundidores quedan unidos a ella por asientos de diez años. A partir de 1717 terminaría el periodo de asentistas y comenzaría la etapa de Directores. Fueron los comandantes de artillería quienes dirigieron la fábrica entonces, convirtiendo el fundidor en un técnico y el director un militar de carrera. Véase: "Inventario de la Real Fábrica de Artillería de Sevilla" editado por la Consejería de Cultura, la Dirección General de Instituciones del patrimonio histórico y el Archivo General de Andalucía, España. http://goo.gl/V3Jzly. (Consulta: 10 de abril de 2014).

58 AGN, Indiferente de Guerra. vol.276; f.1, 
de maestranza fueron movilizados hacia la recién erigida fortaleza de San Carlos de Perote para reanudar las labores en fabricación de armamento, ${ }^{59}$ pero para entonces el personal ya se había reducido a solo dos cabos, un carretero que era "indio leal" y un herrero llamado Joseph Gutiérrez. ${ }^{60}$

El traslado fue propuesto por el ingeniero Diego Panes al virrey Bucareli y Ursúa tras la muerte del anterior director de maestranza Andrés Sanz, justificándose en las constantes disputas de autoridad con el Ministro de Real Hacienda de Veracruz, como había venido sucedido. En esa ocasión también planteó al virrey la necesidad de recontratar personal para la nueva maestranza por la muerte de algunos obreros y el regresó de operarios a la península ${ }^{61}$, el reclutamiento seria de acuerdo a una normatividad inspirada en las ordenanzas de la maestranza de Sevilla. ${ }^{62}$

Una vez que se examinó a cada individuo pretendiente a las vacantes de un sargento de carreteros, dos obreros, un sargento de herreros, un cabo de herreros y otros dos obreros, se comenzó con la producción esperando "la ventaja de instruir la gente del Pays en hacer cureñas, afustes, y otras máquinas”. Pero los trabajadores debían ser contratados no solo por su conocimiento técnicos carpinteros en embarcaciones o herreros diestros en "fragua y lima" sino que fueran "conocidos por españoles” de buenas propiedades y conducta. ${ }^{63}$ Siendo elegidos finalmente cuatro peninsulares y tres americanos. ${ }^{64}$

La producción además corrió a cargo de los sargentos militares que contaron con dos muchachos aprendices. Por los jóvenes le abonaron a cada sargento 15 pe-

59 AGN, Indiferente de Guerra. vol.276; f.6.

60 Desde 1775 se había reducido la plantilla a cargo de Andrés Sanz, quien antes de llegar a Perote se había asentado con todo el personal en México (personalmente considero en Tacubaya) para reparare las cureñas de los cañones ligeros de la capital, AGN, Indiferente de Guerra, vol. 276a, f.1.

61 Desde 1768 habían pedido licencia para regresar a España el Sargento de obreros Fernando Conde con sus dos hijos, uno obrero y el otro aprendiz. AGN, Indiferente de Guerra, vol. 276a. f.3

62 "Instrucción General que hade observar la Maestranza de Artillería que debe trabajar en las Obras dotadas para defensa del fuerte de San Miguel de Perote, ahora nombrado San Carlos". Se hace referencia en algunos puntos que está inspirada en la ordenanza de maestranza del 2 de septiembre de 1736. AGN, Indiferente de Guerra, vol.276a, 35ff.

63 AGN, Indiferente de Guerra, vol. 276a, f.4.

64 AGN, Indiferente de Guerra, vol. 276a, ff.19-30.

Dossier: Artesanos: formas de trabajo, sociabilidades, movilidad social y cultura política en Hispanoamérica, siglos XVI-XX 
sos mensuales comprometiéndose a mantenerlos, "educarlos bien" y adiestrarlos en el oficio de carretero, aserradero, herrero, tornero o "armero del uso de los compas". Esperando para su aceptación como aprendices "buena disposición correspondiente a su hedad" y que todos fueran hijos de españoles, ninguno debía ser indígena, o mulato ni de ninguna casta puesto que los aprendices técnicos tendrían fuero militar. 65

Estos muchachos una vez "matriculados" en la maestranza no podían ser extraídos por sus padres a menos que fuera una razón de causa mayor y bajo licencia del comandante de artillería rectificada por el virrey, debía contar con el aval del tesorero pagador. De igual forma todo certificado por disfunción o licencia de despido de los sargentos, cabos y obreros debía pasar por su visto bueno. ${ }^{66}$

Otra figura de relevancia en la producción fue el tesorero pagador, quien tuvo el trabajo de manejar las escrituras con los permisos otorgados de los padres o parientes a cuyo cargo estuvieran los jóvenes. Además, tuvo el trabajo de contratar y despedir por órdenes superiores a cualquier individuo y brindar cuenta de las relaciones laborales al superior gobierno del Virrey, empezando por los carreteros y concluyendo con los herreros; explicando sus jornales, nombres, destinos y asignaciones de cada empleado, añadiendo los materiales consumidos en cada especie. ${ }^{67}$ Esta cuenta general se haría con base en las libretas de registros que cada sargento (a cargo de muchachos) donde llevaba cuenta de los avances de producción diarios, relación de los materiales entregados para la obra y los "jornales causados en ella" con la anuencia del oficial de artillería. ${ }^{68}$

Todos estarían supeditados a las órdenes del comandante de artillería quien debía contar con dotes técnicas, de mando y contables para, en caso de requerirse, apoyar al tesorero contador. Si este se encontrara ausente o si se realizaran trabajos fuera de San Carlos el oficial encargado debería pasarle dos relaciones donde deta-

\footnotetext{
65 AGN, Indiferente de Guerra, vol. 276a, f.5

66 AGN, Indiferente de Guerra, vol. 276a, f.6

67 AGN, Registros de finanzas, caja 4885, exp.63, f.9.

68 AGN, Indiferente de Guerra, vol. 276a, f.12
} 
llará cada mes de las bajas y altas de obreros, pues al parecer había mucha movilidad en el personal. ${ }^{69}$

Ante esta necesidad de mantener una estable producción en tan fluctuantes condiciones ¿Qué hacer? En los artículos 11 y 12 de la "Instrucción General" de la maestranza se subraya que está permitido que en cualquier momento se puedan anexar maestros y oficiales de todas las clases, voluntarios, soldados facultativos, presidiarios que tuvieran habilidades necesarias para la fabricación de armamento, muchachos huérfanos o lo que se "destierren por mal entretenidos para que vayan instruyéndose en todas facultades por las buenas consecuencias que trahe el servicio del Rey". ${ }^{70}$ Aunque a simple vista el personal convocado parecería heterogéneo, solo a excepción de los presidiarios, ninguno debía ser indígena ni pertenecer a las castas.

Sobre los jornales para los que fueren recién adscritos, estos debían ser asignados por el tesorero pagador con el acuerdo del comandante de artillería (o un oficial en su ausencia) según las aptitudes técnicas de cada obrero. En dado caso que surgiera alguna pieza defectuosa, se tenía que volver a construir o enmendarla, perjudicando al tesorero sobre un descuento de su sueldo. ${ }^{71}$

En caso de que fueran muchachos se le daría una gratificación diaria consultado primero al superior gobierno del virrey. ${ }^{72}$ Parece que la convocatoria a mano de obra fue exitosa pues años después, hacia 1788,73 en la fábrica de armamento se encontraban presidiarios que fueron destinados a los trabajos más "robustos" y fueron escogidos por el oficial al mando de la artillería para mayormente los trabajos en maniobras y carga de piezas de los almacenes y la sala de armas. ${ }^{74}$ También para entonces hubo un número de muchachos huérfanos que laboraron los oficios

69 "Empezando por la profesión de carreteros, y otra de los jornaleros que se han empleado con expresión de sus nombres, sus destinos, asignación de jornales que han devengado, altas, y vajas de ellos, y al fin del mes, una relación general década especie, que comprehenda todas las semanales, y otras de los materiales convenidos en aquel mes". AGN, Indiferente de Guerra, vol. 276a, f.8

70 AGN, Indiferente de Guerra, vol. 276a, ff.8-9.

71 AGN, Indiferente de Guerra, vol. 276a, f.9.

72 AGN, Indiferente de Guerra, vol. 276a, ff.8-9.

73 Tenemos constancia de ello para 1788. AGN, Registros de finanzas, caja 4885, exp.63, f.9.

74 AGN, Registros de finanzas, caja 4885, exp.63, f.119v.

Dossier: Artesanos: formas de trabajo, sociabilidades, movilidad social y cultura política en Hispanoamérica, siglos XVI-XX 
de maestranza, siendo instruidos "con todas sus facultades". ${ }^{75} \mathrm{El}$ tesorero pagador fue el encargado de firmar el acuerdo con el comandante en artillería sobre el tema de los presidiarios, la Corona los mantuvo con labores mientras cumplían con toda su condena. ${ }^{76}$

El tesorero fue el administrador de los pagos para todos los operarios junto con la presencia del oficial de artillería, (encargado del detalle, o de los sargentos obreros a su falta) él siempre tuvo que entregar la cuenta y razón a sus superiores, anotando los pagos mensuales detallados en la tabla 12,77 pasándole lista a cada individuo sobre sus jornales y para que pudiera aprontar la solicitud de materiales. El tesorero tuvo prohibido darles libertad a los trabajadores de extraer pertrechos y géneros de los almacenes de artillería sin algún documento que fuera validado por el oficial artillero. ${ }^{78}$

Otra autoridad vital para la producción fue el oficial de artillería, encargado de la maestranza, también se avocó a distribuir entre el sargento y los cabos de obreros los materiales respectivos de manera proporcional a sus necesidades, llevando un libro de registros con detalles sobre el peso, número y medida de los materiales entregados y también de los que se gastaban, como el carbón..$^{79}$ Con las cuentas generales se hacía un relación certificada por el oficial explicando el acero, herraje, madera y clavazón y demás materiales empleados en cada cosa para que una vez aprobado por el tesorero pagador, el comandante de artillería le dé el visto bueno se pasase a realizar "el correspondiente abono de todo lo consumido". ${ }^{80} \mathrm{Si}$ llegaba a faltar algún pertrecho que recibieron para el "trabajo de sus facultades" seria descontado del sueldo del sargento de obreros para que estos tuviera "el recurso contra los operarios que se justificase haber sido causa del extravío". ${ }^{81}$

75 AGN, Registros de finanzas, caja 4885, exp.63, f.9.

76 AGN, Registros de finanzas, caja 4885, exp.63, f.9v.

77 Fueron los mismos que cuando la maestranza estuvo asentada en Veracruz en 1768. Si algún empleado no siguiera las normas no recibiría pago alguno aunque lo justificara algún cabo. AGN, Indiferente de Guerra, vol. 276a, ff. 4 y 18.

78 AGN, Indiferente de Guerra, vol. 276a, f.10

79 AGN, Registros de finanzas, caja 4885, exp.63, f.9v.

80 AGN, Indiferente de Guerra, vol. 276a, f.11

81 AGN, Indiferente de Guerra, vol. 276a, ff.11-12. 
Esto nos señala que la necesidad de materiales fue constante preocupación en la producción de la maestranza, desde el primer año de su arranque, en 1778; ordenado por el virrey Bucaralli se hizo un reconocimiento por parte de Francisco de Ortúzar del estado de las minas cercanas a Perote para saber si su explotación sería conveniente para la fabricación de cañones. Se recorrieron las minas "Santísima Trinidad", "Santa Rosa de Lima" y "San Carlos" en las Barrancas de Tenepanoya. Mientras que en el paraje de Temextla se visitó "Santa Gertrudis" y "Nuestra Señora de la Luz" para tomar muestras de su producción de cobre. Según los resultados obtenidos por Francisco de Ortúza, en marzo de 1778, este cobre era de muy buena calidad para crear artillería de bronce purificándolos con un 10\% de estaño fino. ${ }^{82}$ Aunque es probable, en el estado actual de la investigación no encontré constancia alguna de su utilización.

Por otra parte, puedo aseverar que la producción de la maestranza de Perote fue de tal envergadura que afectó los recursos forestales en tan solo unos años. Un año antes de la instalación de la maestranza, en 1777, el ingeniero Miguel del Corral había realizado una expedición a la zona encontrado grandes bosques de pino a la orilla de la meseta cerca de Perote, consideró que eran muy aptos para su explotación y envió muestras en cajas embaladas a Madrid. ${ }^{83}$ Pero, para 1785 se hacía referencia a la amplia desforestación de la zona pues hubo una indiscriminada tala con el fin acopiarse de las maderas necesarias para la construcción de pertrechos de artillería, es decir de las cureñas, "para proveer a las fortificaciones, guarniciones y baterías que convenga". 84

Volviendo al tema de los trabajadores en relación con los materiales, además de que estaba estrictamente prohibido que se sacara cualquier tipo de género inclusive astillas o virutas de madera, mucho menos herramientas, clavos o carbón sin una orden legitima del comandante de artillería (los detalles del tipo de herramientas están en la tabla 13). Inclusive para fines de limpieza de las instalaciones se ne-

82 AGI, Indiferente General. Caja 1901, exp.12, Informe de Pedro Ponce sobre el reconocimiento de las minas. Perote 13 de marzo de 1778.

83 Alfred Siemens, "El sur de Veracruz a finales del siglo XVIII. Un análisis de la relación de Corral”, en Historia Mexicana n. ${ }^{\circ}$ 2. México D. F., El Colegio de México, 1976, p.279

84 AGN, Indiferente de Guerra. Caja 3370, exp.16. Carta de Marcos Keating al Exmo. Virrey Conde de Gálvez. Marzo de 1785 .

Dossier: Artesanos: formas de trabajo, sociabilidades, movilidad social y cultura política en Hispanoamérica, siglos XVI-XX 
cesitaba avisar al tesorero apara que conviniera en que paraje se tirarían los escombros. ${ }^{85}$

A los obreros nunca se les dejo solos durante sus labores, por el motivo de que algún dependiente de maestranza durante las horas de trabajo las ocupara en obras ajenas en lugar de disponerse al real servicio. Para que la administración evitara estos casos durante la producción el tesorero podía entrar a las obras siempre que desease, pasando a supervisar las maestranzas con un acuerdo del comandante en artillería. Otra normatividad a seguir es que el encargado en maestranza que fuera encontrado rompiendo las instrucciones sobre los trabajadores, seria nominado como un delincuente infractor y solo multado, ${ }^{86}$ de igual forma todo aquel obrero que estuvo laborando en cosas ajenas a la maestranza o que se ausentara sin justificar su paradero se le castigó cual "mismo delincuente". 87

Para guardar este "buen régimen de la maestranza" había un cepo y un calabozo "para los que sean necesario mortificar",, 8 "siempre que por unos ú otros se cometiere algún fraude sabiendo el motivo de la prisión el ministro Pagador, y siendo de ello sabedor el comandante, mandará sele castigue, según el caso lo pidiere". ${ }^{89}$ Para colaborar al sometimiento de desórdenes, robo, rencillas, oposición al servicio o embriaguez se dispuso una guardia de tropa de artillería compuesta por un sargento, un cabo, cuatro artilleros bajo las órdenes del comandante. Esta guardia además debía auxiliar al pagador en todo lo que se requiriese para conservar su autoridad delante de los obreros. ${ }^{90}$

Con respectos a los horarios de los obreros, sus jornadas durante el verano comenzaban de 6 de la mañana hasta el mediodía y regresar de 2 a 6:30 de la tarde con un receso para desayunar de 8 a 8:30 de la mañana. Las jornadas en el invierno fueron variables según las horas que les fueran señaladas. Todo el que faltara a su horario de trabajo (llegando tarde o saliendo antes) se le descontaría todo el jornal de aquella mañana, tarde o si es "de plaza sentada" (sargento o cabo de obreros) se

85 AGN, Indiferente de Guerra, vol. 276a, f.15.

86 AGN, Registros de finanzas, caja 4885, exp.63, f.13.

87 AGN, Indiferente de Guerra, vol. 276a, f.12

88 AGN, Indiferente de Guerra, vol. 276a, f.14

89 AGN, Indiferente de Guerra, vol. 276a, f.15

90 AGN, Indiferente de Guerra, vol. 276a, f.13 
le castigará según lo merezca su superior. ${ }^{91}$ El tesorero pagador siguió el mismo horario, pasando lista a los sargentos, cabos y obreros de plaza y a los demás peones, y apunto los retardos y a los trabajadores que no se encontraban para que la real hacienda no sufriera gastos indebidos. El tesorero inclusive tuvo que resguardar que los operarios "trabajaran con celo y aplicación" en sus áreas correspondientes y todo aquel que no lo hiciera se le descontaban de su sueldo o despedían. ${ }^{92}$

Cuando grupos de las maestranzas se dedicaron a trabajar en parajes distantes del poblado de Perote para el acopio de insumos, la obra se tuvo que proveer de víveres. Se prohibió que cualquier tendero o vivandero pudiera establecerse o hacer trato sin alguna licencia que estuviera escrita por el comandante de artillería y el tesorero, o sin previo reconocimiento e informe del oficial que se encontrara encargado de las obras, analizando que no hubiera género ni comestibles nocivos y de mala calidad para los trabajadores, ni de los prohibidos por las leyes: Bayucas, venta de caldos y "vevidas prohibidas" pues ha de procurarse "la mayor observancia" de los sujetos por la responsabilidad que tienen. ${ }^{93} \mathrm{Ni}$ el comandante, el oficial en detalle, ni el pagador debían exigir gratificación alguna de los tenderos o vivanderos, por el cargo que ellos tenían, tampoco la justicia del territorio donde se trabajó la maestranza. ${ }^{94}$

Existió una igual prohibición para la entrada de mujeres a la maestranza, el cabo de guardia fue el encargado de vigilar que ninguna esposa de los obreros pretextando llevar el almuerzo u otra cosa entrara en las instalaciones en las horas de trabajo puesto que podrían distraer e interrumpir las obras, extendiéndose esta prohibición también para clérigos y religiosos. Cuando salieran al desayuno, aque-

91 AGN, Indiferente de Guerra, vol. 276a, f.13

92 Se podría decir que el temperamento fue un factor importante ya que el Antonio de Ulloa nos describe como en esa temporalidad se encontraba el clima. Se reconoce frio desde el malpaís en adelante. A las seis de la mañana en las vigas el termómetro marcaba once grados y a las once del día en el pueblo de Perote 18 con tiempo claro y el viento moderado por el noreste. Ana Laura Delgado, Cien Viajeros en Veracruz: crónicas y relatos, t.II, Xalapa, Gobierno del Estado de Veracruz, 1992, p.97.

93 AGN, Indiferente de Guerra, vol. 276a, f.16

94 AGN, registros de finanzas, caja 4885, exp.63, f.13.

Dossier: Artesanos: formas de trabajo, sociabilidades, movilidad social y cultura política en Hispanoamérica, siglos XVI-XX 
llos obreros que sus mujeres o familiares les hubieran llevado algo, deberían comer siempre delante del guardia. ${ }^{95}$

Durante la producción de armamento el tesorero revisó durante todos los meses de cada año las funciones de los sargentos, cabos, obreros y aprendices de plaza asentada, que estuvieron enfocados en la maestranza, anotando sus altas y bajas junto con el abono de pago de cada operario en su oficio. El tesorero o el encargado de la obra hicieron que se firmara en el libro de gastos todos los sujetos del cuerpo de artillería, para el goce de sueldos, respetando que recibieran ni más cantidad ni menos de su remuneración acordada. Los sargentos tuvieron un honorario de 53 pesos al mes, los cabos de 72 pesos restándoles 30 para el pago de sus obreros y sus aprendices con 15 pesos para cada uno. ${ }^{96}$

Los proyectos no se pudieron aprobar sin autorización del personal que se encontraba a cargo o por órdenes superiores, desde cualquier actividad u obra de la maestranza. Los materiales que se emplearon corrieron por cuenta de la administración o por algún trato del tesorero pagador o por parte del ingeniero Santisteban. Sobre todo, cuando necesitaron alimentarse de las ministras para los forzados y muchachos, procurando seguir un orden sobre el almacenamiento y distribución de los alimentos. ${ }^{97}$

El tesorero pagador elaboró un inventario general del número de cañones, morteros, cureñas, avantrenes, placas, armamentos y demás anexos que existieron adentro del fuerte, especificando los calibres, especies, calidades, peso, número y medidas que tuvieron. Todas las armas las entregaron al guarda almacén para que él las dispusiera, todo armamento que no conservó bajo sus llaves estuvo al cuidado y responsabilidad del comandante en artillería y el oficial de detalle; de todas tuvo que entregar un recibo a sus superiores por todo lo que gastaron. El tesorero pagador tuvo un texto similar, a los libros del guarda almacén que contó con dos ejemplares, en el que asentaron todos los días del año, la distinción de los trabajadores con sus ramos, cargos y otras actividades sobre las tareas de maestranza. El guarda almacén recibió los datos de los materiales junto con el oficial de artillería en dichos libros. Para los gastos que a diario ocurrieron en los almacenes, el tesorero le brindaba una corta cantidad al guarda almacén, en una relación jurada entre ellos

95 AGN, Indiferente de Guerra, vol.276a, ff.15-16

96 AGN, registros de finanzas, caja 4885, exp.63, f.15.

97 AGN, registros de finanzas, caja 4885, exp.63, f.15v. 
antes de que recibieran otra cuota, cuyo documento sirvió para los datos del tesorero pagador. 98

Se debían sacar a limpiar y sacudir las cureñas sobrantes guardadas en los almacenes por lo menos cada tres meses, así tal vez se podía prevenir cuando alguna llegara a necesitar composición de sus piezas de madera o fierro y evitar las demoras en la cadena de abastecimiento burocrática en favor de un menor gasto. Se facilitaría por parte del tesorero pagador los menesteres precisos siempre que diera una orden el guarda almacén para que se suministrara las piezas necesarias a los reparos, avisando primero al oficial de artillería cuales eran. También se tenían que remover con frecuencia las cureñas montadas, para que la gravedad del peso de los cañones no lastimara las ruedas, dejándolas cargar por un solo paraje, y ofreciendo algunas composiciones, aunque esto hubiese sido leve y se dispondría prontamente lo necesario en los términos que previniera el artículo anterior. El guarda almacén siempre daba una orden a los trabajadores para que suministraran las piezas necesarias a los reparos y ellos tenían que avisar primeramente al oficial en artillería, que armas se arreglarían al principio. ${ }^{99}$

El maestro armero, tuvo que tener un reconocimiento por parte del guarda almacén, en presencia del ayudante u oficial comisionado arriero, para que él pudiera recibir el armamento que aún seguía llegando de España o de otro paraje del reino para su compostura, él tuvo que apuntar las faltas y defectos de las armas, explicando su cantidad, calidad y servicio de cada una de éstas, junto con sus precios. 100

En ocasiones se entregaron armas de los almacenes, para brindarle municiones algunos cuerpos de tropa. El servicio de artillería se dedicó a comprar municiones, pertrechos y efectos. El tesorero pagador y el oficial de detalle calificaban las compras que si eran buenas o malas porque tenían que hacer uso de ellas. ${ }^{101}$

98 AGN, registros de finanzas, caja 4885, exp.63, f.17v.

99 AGN, registros de finanzas, caja 4885, exp.63, f.18.

$100 \mathrm{El}$ armamento fue también objeto de revisión y de reglamentación, fundamentalmente para lograr una mayor operatividad de cara a la defensa del imperio pero también, para ofrecer una imagen acorde con la carrera militar. Carmen Gómez, El sistema defensivo americano. Siglo XVIII, Madrid, MAPFRE, 1992, p.97.

101 AGN, Registros de finanzas, caja 4885, exp.63, f.119v.

Dossier: Artesanos: formas de trabajo, sociabilidades, movilidad social y cultura política en Hispanoamérica, siglos XVI-XX 
Cuando hubo una falta de trabajadores el guarda almacén utilizó a los peones libres que se necesitaron, satisfaciendo sus horas de labor, justificando todos sus pagos con las formalidades precisas. No obstante un oficial mandaba la artillería a manos del tesorero, para su debida revisión y que el diera su punto de vista, dando su calificación, porque toda arma debía de contar con su distinciones, simetrías, que estuvieran con el mayor aseo y cuidado, para que así previniera al guarda almacén y pasaran a la sala de armas. ${ }^{102}$

Las armas estuvieron en mantenimiento durante la vida militar de la fortaleza. Los obreros con el cargo de reparación de piezas de madera o fierro le solicitaban al tesorero pagador que les facilitara una suma de dinero sin demora alguna, para los menesteres precisos y que no causaran un mayor gasto para la producción, ${ }^{103}$ la que continuo durante el siglo XVIII y durante las primeras décadas del siglo siguiente. ${ }^{104}$ Por desgracia, no se cuenta aún con estudios especializados sobre el mundo del trabajo o la producción de armamento en Perote, salvo escuetas referencias sobre proyectos alternos e inconclusos, ${ }^{105} \mathrm{o}$ solo mencionando su existencia brevemente en notas al pie de página.

Aunque las maestranzas no se han estudiado a detalle y si bien a lo largo de esta concisa investigación no he encontrado datos exactos sobre el número de piezas que se fabricaron o a qué ritmo, si puedo aseverar que la producción en Perote se especializó en el armado y recomposición de piezas de artillería mucho más que en fusiles o escopetas. Carmen Gómez inclusive anota brevemente que Perote fue un centro fundamental de fabricación de armamento y que su producción abasteció al gran caribe español gracias a la siguiente red de distribución: saliendo de la maestranza las piezas alcanzaban primero Campeche, Santo Domingo, la Habana y Puerto Rico, esta última se dotaba tanto de la producción de armamento de España

102 AGN, Registros de finanzas, caja 4885, exp.63, f.14v.

103 AGN, registros de finanzas, caja 4885, exp.63, f.18.

104 Existen menciones de que la maestranza de Perote continúo en actividades inclusive décadas después de la independencia de México. Hacia septiembre de 1838 se discutía su cierre pero resultaba inviable ante el escenario bélico contra los franceses en la conocida "guerra de los pasteles" Juan Almonte, Memoria de Ministro de Guerra y Marina, presentada a las cámaras del Congreso General Mexicano, en Enero de 1840, México D. F., Oficina el Águila, 1840, p.17

105 Véase Ascensión Baeza, "Fundición de Artillería en Nueva España: Proyectos Fallidos, la alternativa de Sevilla (1722-1794)", en María Luisa Laviana (coord.), Estudios sobre América; Siglos XVIXX, vol.1, Sevilla, Asociación Española de Americanistas, 2005, pp.879-903 
como con la de Nueva España. ${ }^{106}$ Un apunte más para vislumbrar la capacidad de producción que tuvo la maestranza es que fue uno de los factores para impulsar el proyecto "modernizante" de ampliar el camino real vía Xalapa, pues su abastecimiento requirió una serie de condiciones para su buen funcionamiento. Una de ellas una era contar con una vía capaz de transportar la mayor posible cantidad de artillería armada o reparada y víveres para los trabajadores. Aspecto que se pone de manifiesto es las órdenes del virrey para el constante arreglo del camino. ${ }^{107}$

Al parecer la erección de una infraestructura que, para entonces, era de tecnología de punta, fue demasiado ventajosa para limitarla solo a la producción de armamento ante una invasión militar que seguía sin llegar. En 1782 todas las herramientas, el material y la experiencia de los obreros que se había acumulado para fabricar cureñas (partes que sostiene el cañón y que está dotada de eje y ruedas para movilizar las piezas) se redireccionó para fabricar lo que para entonces resultaba más acuciante, aunque fuera para la esfera civil. Fernando Messia presentó un resumen de gastos a la Real Hacienda donde señalaba que se habían gastado 36.000 pesos en fabricar carromatos a cuenta de esta, y que se había comenzado a trabajar en estos coches gracias a los medios técnicos que solamente tenía la maestranza de Perote, por desgracia la construcción de carromatos se abandonó por motivos fiscales al año siguiente. ${ }^{108}$

La presencia articuladora local de comerciantes y vivanderos que quisieron sacar provecho monetario de las obras, al igual que la existencia de una compleja cadena de abastecimiento de insumos hacia dentro, y otra aún más compleja cadena de distribución de la producción allende los mares, constituyen un soporte para argumentar que existió una verdadera fase de trabajo proto-industrial bajo los auspicios de la Corona en Nueva España; y que, además de los obrajes, existió un pro-

\footnotetext{
106 Señala brevemente que México fue un productor de armamentos privilegiado en la América española pues contaba con una fundición de cañones en Tacubaya, una fábrica de armamentos en Perote y una fábrica de pólvora en Chapultepec. La red de distribución saliendo de estas fábricas alcanzaba también Veracruz, que redistribuía al resto del virreinato. Carmen Gómez, "El problema logístico y la operatividad de la artillería en América" en Militaría. Revista de Historia militar n. ${ }^{\circ}$ 10, Madrid, Universidad Complutense de Madrid, 1997, p.46.

107 AGN, Caminos y Calzadas, vol.11, exp.2, ff.52-6o, Ordenes del virrey Martín de Mayorga, sobre que del producto de alcabalas de Xalapa se pague la herramienta y jornales de los trabajadores que se emplearan en la reparación del camino que va de Veracruz a Perote, México, 1784.

108 Vicente Rodríguez, El fiscal de Real Hacienda en Nueva España: Don Ramón de Posada y Soto, 1781-1793, Oviedo, Universidad de Oviedo, 1985, p.156.
} 
ceso de consolidación de espacios dedicados exclusivamente a cierto tipo de producción con trabajo especializado y que fueron de prioridad estratégica para las autoridades virreinales. ${ }^{109}$

Las maestranzas, como la de Perote, fueron los centros más importantes de labor dentro de lo que jurídicamente se llamó "Reales obras", concentrando gran número de individuos cuyos jornales eran más elevados en comparación al resto del artesanado. Sus habilidades en carpintería, herrería, fundición y armería los convertían en un sector privilegiado de trabajadores, pues sus actividades estaban estrechamente relacionadas con el resguardo del sistema económico trasatlántico. Aunque su formación fue una limitación para el ascenso social de las castas ${ }^{110}$ esta debe entenderse en el contexto del despotismo ilustrado, cuyo objetivo fue situar a los artistas y artesanos al servicio del Estado.

\section{A modo de conclusión}

La labor en el antiguo régimen novohispano se presta a una amplia gama de análisis por sus variadas tipologías, esta investigación se ha enfocado en dos mundos del trabajo alejados por su concepción de no requerir "ni arte, ni habilidad" por parte de los peones en la construcción o ser operarios y obreros de orden técnico y estratégico, pero ambos obrando en un mismo espacio: San Carlos de Perote. Dentro de estos orbes en que se vieron inmersos los actores sociales existió una serie de categorías comunes cuya convergencia permite entender mejor su vivencia cotidiana, con el fin de acercarnos tentativamente a lo que conllevó la experiencia laboral de fines del siglo XVIII.

109 Sin confundir esta fase con el proceso de industrialización que solo se producirá de manera parcial en el ocaso del siglo siguiente. Manuel Miño, La protoindustria colonial en Hispanoamérica, México D. F., El Colegio de México/Fideicomiso Historia de las Américas/FCE, 1993, p.18

110 Desde la historia social existe un estudio que aborda otra maestranza y nos permite hacer una comparativa interesante. En Cartagena de Indias los jornales de los artesanos mayores (armeros, carpinteros y herreros) rondaban los 15 pesos mensuales, equivalente a los jornales de los aprendices de Perote y la mitad del jornal de sus equivalentes novohispanos ¿Una inflación local? ¿Fue acaso indicador del nivel de su producción? Sergio Paolo Solano, "Sistema de defensa, artesanado y sociedad en el Nuevo Reino de Granada. El caso de Cartagena de Indias, 1750-1810", en Memorias vol.10, n. ${ }^{\circ}$ 19, Barranquilla, Universidad del Norte, 2013, pp.92-139; Sergio Paolo Solano y Roicer Flórez, "Artilleros pardos y morenos artistas: artesanos, raza, milicias y reconocimiento social en el Nuevo Reino de Granada, 1770-1812”, en Historia Critica n. ${ }^{\circ}$ 48, Bogotá, Universidad de los Andes, 2012, pp.11-37. 
Las medidas disciplinarias fueron una constante en ambos ramos laborales. $\mathrm{Si}$ en la construcción las alteraciones al ritmo de la obra se castigaron con apercibimientos y labores pesadas, en la maestranza se sometieron a una disciplina cercana al mismo fin de la producción, es decir al ámbito militar, con castigos físicos y privación de la libertad. También en ambos mundos laborales coexistió trabajo forzado y libre pero su reclutamiento y proporción puede ser indicador de un punto de quiebre en las concepciones del trabajo. ${ }^{111}$

El reclutamiento se dio de formas distintas en ambos mundos pero tuvo variables semejantes. Los peones de la construcción fueron enganchados en dos etapas distintas, al ser un proyecto directamente impulsado por la Corona esta tuvo que garantizar la primera oleada mediante forzados. Estos a su vez se reclutaron por "leva de vagos" de las cercanías y un flujo intermitente de solicitados al virrey en calidad de "presidiarios". En ambas formas de trabajo impuesto existió un discurso que las justificó por las "buenas consecuencias que trahe el servicio del Rey" ponderando el bien público por sobre el del particular súbdito.

La segunda etapa de reclutamiento corrió a cargo de peones libres, pero, ¿Por qué habrían de preferir los peones la construcción que sus labores agrícolas? Se nota en la documentación que la conexión de los trabajadores con su medio social fue estrecha, al ser una zona de intensa arriería y alto crecimiento económico por la actividad agropecuaria transferir mano de obra de estas redituables labores a los requerimientos de un trabajo que requería constancia a lo largo de varios años no resultó tarea sencilla.

El mecanismo consistió inicialmente en ofrecer un salario promedio por día a los vecinos de San Miguel de Perote pues se temía que huyeran. Una vez consolidada esta base se procedió a ofrecer paga por mes, con lo que se atrajo a peones de las cercanías. El último método de reclutamiento de libres fue muy parecido al de los forzados, pues se dio por intervención de la autoridad central, consiguiendo que autoridades locales de villas más alejadas reclutaran y enviaran cuadrillas de albañiles. Al respecto Ruggiero Romano menciona que la distinción entre trabajo libre

111 Silvio Zavala da cuenta del mismo proceso en tres fases de desarrollo: una esclavitud efímera, remplazo por trabajo forzoso o compulsivo y finalmente el impulso del trabajo libre. Silvio Zavala, "La evolución del régimen de trabajo" en Ensayos sobre la colonización española en América, Buenos Aires, Emecé, 1944, pp.123-134. 
$\mathrm{y}$ forzado fue a veces relativa, y que en el interior del trabajo libre se dieron formas, como esta, de "compulsión indirecta”. ${ }^{112}$

Estas bandas enganchadas fueron estacionales y rotaron una vez al mes como una forma de asegurar que estuvieran "frescas y saludables". Sobre todo, al ser los peones eminentemente de extracción indígena campesina y esperando mayor volatilidad de mano de obra en los meses de cosecha en otoño y durante la siembra antes del verano (como ocurrió en junio de 1772), se aplicó para asegurar que no se detuvieran las obras. Dicho movimiento no implicó necesariamente el transito del trabajo corporativo ligado a las repúblicas de indios a un trabajo indígena asociado desvinculado de los pueblos puesto que, además de lo anterior, existieron "licencias de retiro" temporario como síntoma de que los constructores laboraron también como campesinos de medio tiempo

Por otra parte, el reclutamiento de los obreros y operarios de la maestranza fue limitado y reglamentado por su carácter altamente calificado. Se partió en un primer momento de la necesidad de llenar las plazas vacantes, realizando una convocatoria, el resultado fue una restricción de pureza de sangre pues se requería, a diferencia de los constructores de la fortaleza, que fueran "españoles" por su fuero militar. Fue un reclutamiento cerrado entre los mismos individuos de la maestranza anterior de Veracruz, siendo 3 sevillanos y un catalán a los que se anexó muy probablemente algunos obreros que habían trabajado en la anterior maestranza de Tacubaya pues aparecen en la documentación 2 como originarios de México y uno más oriundo de Tevistlan. ${ }^{113}$

Una vez cubiertas las plazas en convocatoria se requirió también de mano de obra auxiliar por parte de jóvenes que se anexaron a solicitud de sus padres o al ser huérfanos por voluntad propia. Estos también debían ser considerados "españoles" de buena conducta y muy probablemente fueron de extracción urbana cercana, como Xalapa o Puebla. Las actividades que realizó este grupo "matriculado" (como aparece en la documentación) asemejó a una labor técnica y al mismo tiempo una educación en academia militar, puesto que en una sociedad sin industria apenas, con universidad sin reforma en "ciencias útiles", con la estructura productiva organizada gremialmente y con la reciente expulsión de los jesuitas, solo los militares

112 Ruggiero Romano, "El trabajo compulsivo y trabajo libre en Nueva España (siglos XVI-XVIII)", en Ángel Vaca (ed.), El trabajo en la historia, Salamanca, Universidad de Salamanca, 1996, p.204

113 AGN, Indiferente de Guerra, vol.276A, ff.19-30. 
podrían proporcionar una educación científica y técnica a las nuevas generaciones en un proceso que se ha denominado "militarización de la ciencia ilustrada" en la Corona española. ${ }^{114}$

La segunda etapa del proceso de reclutamiento para los trabajos de la maestranza debió estar ligado a un aumento en las necesidades de producción, pues a pesar de que en un principio las labores estuvieron restringida al personal "de plaza”, pronto se abrió a cualquier individuo con habilidades en carpintería naval y en herrería; maestros artesanos, oficiales y soldados podrían laborar como obreros. Fue tal la necesidad de manos en la fabricación y reparo de armamento que inclusive se solicitaron forzados en calidad de presidiarios, siendo los únicos miembros de castas por ser peones para tareas "robustas".

Aun así, ¿Por qué existieron más trabajadores libres que forzados? En ambas actividades la balanza se inclinó debido a la necesidad de laborar en empresas que requerían exactitud, como el elevar una plataforma con cierto ángulo para colocar la artillería o el darle mantenimiento a tecnología de punta, pues peones incentivados podrían laborar con aun más precisión que personal obligado. Asimismo, resulta indudable que las redituables actividades económicas en la región central de Veracruz fueron un factor importante, puesto que no se podría reclutar a grandes cantidades de mano de obra que interfirieran en las ganancias de las elites locales "españolas", entonces se ofrecieron unas remuneraciones en aumento para captarla de manera temporaria. Por último, este carácter pecuniario de la retribución solo pudo ser sostenido por una exitosa fiscalización centralizada y esta a su vez impulsada por las nuevas prioridades militares, obrando en pos de la defensa de una región bisagra dentro del sistema económico de la monarquía. ${ }^{115}$

114 Enrique Martínez et al, Ilustración, ciencia y técnica en el siglo XVIII español, Valencia, Universitat de Valencia, 2008, pp.259-260; Eduardo Martiré, "La militarización de la monarquía borbónica. (¿Una monarquía militar?)”, en Feliciano Barrios (coord.), El gobierno de un mundo: virreinatos y audiencias en la América Hispana, Cuenca, Ediciones de la Universidad de Castilla-La Mancha, 2004, pp.458-463

115 Antonio García de León, Tierra adentro, mar en fuera. El puerto de Veracruz y su litoral a sotavento. 1519-1821, México D.F., FCE/Secretaria de Educación del Estado de Veracruz/Universidad Veracruzana, 2011, p.636 


\section{ANEXOS}

Tabla 1: Numero de las herramientas de trabajo

\begin{tabular}{|l|c|}
\hline \multicolumn{1}{|c|}{ Herramientas } & Número \\
\hline Palas & 2.000 \\
\hline Picos & 2.000 \\
\hline Azadas & 2.000 \\
\hline Estriochas & 2.000 \\
\hline Hachas & 100 \\
\hline Barretas y palanquetas & 200 \\
\hline TOTAL Animales y herramienta & 8.300. \\
\hline \multicolumn{1}{|c|}{ Anima } \\
\hline 60o Mulas & Costo \\
\hline 6o Carretas & 6.000 pesos \\
\hline Total 660 & 600 pesos \\
\hline
\end{tabular}

Fuente: AGN, Reales Cedulas. Originales y duplicados. Exp.77. Historia del Catillo de San Carlos, vol.III, f.3; AGN, Reales Cedulas, Originales y duplicados, exp. 77, f.29

Tabla 3: Gastos, empleados, herramientas y cuenta del mes

\begin{tabular}{|c|l|c|}
\hline $\begin{array}{c}\text { Cuenta del } \\
\text { mes }\end{array}$ & \multicolumn{1}{c|}{ Gastos diarios } & \multicolumn{1}{c|}{ Total } \\
\hline 50 & Carreteros a 2 reales & 12 carreteros \\
\hline 2 & Maestros de carros a 4 reales & 1 Maestro de carro \\
\hline 6 & Mayorales a reales & 3 Mayorales reales \\
\hline 4 & Sabaneros 2 reales & 1 Sabanero \\
\hline 8 & Mayordomo 1 peso & 1 Mayordomo \\
\hline 20 & Fanegas de maíz 1 peso & 2 Fanegas de maíz \\
\hline$\dot{¿} ?$ & Cebada que comían las mulas en los & 4 bultos de cebada \\
\hline$\dot{¿} ?$ & 6o días 4 pesos & 23 \\
\hline
\end{tabular}

Fuente: AGN, Reales Cedulas, Originales y duplicados, exp. 77, ff. 29r.-v. 116

116 Los materiales en listado en la tabla anterior estuvieron fechados el día 23 de mayo de 1770. 
Tabla 4: Nombres, ocupaciones y sueldos de los empleados

\begin{tabular}{|c|c|c|c|c|c|}
\hline Nombres & Ocupación & Sueldo & Nombres & Ocupación & Sueldo \\
\hline Juan Vicente & Cantero & 4 días 2 pesos & Marco Juan & Carpintero & $\begin{array}{l}6 \text { días } \\
2 \text { pesos }\end{array}$ \\
\hline Don Pueyo & $\begin{array}{c}\text { Maestro } \\
\text { Carpintero }\end{array}$ & 30 pesos & $\begin{array}{l}\text { Antonio } \\
\text { Hernández }\end{array}$ & Carpintero & 5 días 1 peso \\
\hline $\begin{array}{l}\text { Don Cristóbal } \\
\text { Martin }\end{array}$ & Guarda Parque & 20 pesos & Juan Bautista & Carpintero & $\begin{array}{l}4 \text { días } \\
2 \text { pesos }\end{array}$ \\
\hline $\begin{array}{l}\text { Don Andrés } \\
\text { de María y } \\
\text { Díaz }\end{array}$ & Carpintero & 6 días 3 pesos & Isidro Ortiz & Carpintero & $\begin{array}{l}4 \text { días } \\
2 \text { pesos }\end{array}$ \\
\hline Don Juan & Carpintero & 6 días 3 pesos & Joseph Barredas & Carpintero & $\begin{array}{l}4 \text { días } \\
2 \text { pesos }\end{array}$ \\
\hline Rafael & Carpintero & 6 días 3 pesos & Alonzo García & Carpintero & $\begin{array}{l}4 \text { días } \\
2 \text { pesos }\end{array}$ \\
\hline $\begin{array}{l}\text { Don Nicolás } \\
\text { Jerónimo }\end{array}$ & Carpintero & 6 días 3 pesos & Juan Cárdenas & Cantero & $\begin{array}{l}2 \text { días } \\
2 \text { pesos }\end{array}$ \\
\hline Don Iván & Carpintero & 6 días 1 peso & $\begin{array}{l}\text { Seferino } \\
\text { Cárdenas }\end{array}$ & Cantero & $\begin{array}{l}4 \text { días } \\
2 \text { pesos }\end{array}$ \\
\hline Don Jerónimo & Carpintero & 6 días 2 pesos & Pablo Antonio & Cantero & $\begin{array}{l}9 \text { días } \\
2 \text { pesos }\end{array}$ \\
\hline $\begin{array}{l}\text { Martin } \\
\text { Jerónimo }\end{array}$ & Carpintero & 6 días 2 pesos & Thomas Adán & Cantero & $\begin{array}{l}4 \text { días } \\
2 \text { pesos }\end{array}$ \\
\hline Juan Menezas & Carpintero & 6 días 2 pesos & Ignacio Cárdenas & Cantero & $\begin{array}{l}9 \text { días } \\
2 \text { pesos }\end{array}$ \\
\hline Juan Pablo & Carpintero & 6 días 2 pesos & Miguel Mariano & Cantero & 4 días 1 peso \\
\hline Miguel Martin & Carpintero & 6 días 4 pesos & Juan Ignacio & Carpintero & 2 días 1 peso \\
\hline Miguel Rafael & Carpintero & 6 días 2 pesos & Franco de la Cruz & Carpintero & 2 días 1 peso \\
\hline $\begin{array}{l}\text { Nicolás } \\
\text { Antonio }\end{array}$ & Carpintero & 6 días 2 pesos & & & \\
\hline
\end{tabular}

Fuente: AGN, Reales Cedulas, Originales y duplicados, exp. 77, f.102v.

Tabla 5: Nombres y sueldos de los partidores de piedra

\begin{tabular}{|l|c|c|}
\hline \multicolumn{1}{|c|}{ Nombres } & Ocupación & Sueldo \\
\hline Juan Gerardo & Partidor & 4 días 1 peso \\
\hline Manuel Antonio & Partidor & 9 días 2 pesos \\
\hline Leonardo Adam & Partidor & 3 días 1 peso \\
\hline José Moreno & Partidor & 4 días 1 peso \\
\hline Pascual García & Partidor & 9 días 2 pesos \\
\hline Juan Antonio & Partidor & 9 días 2 pesos \\
\hline Francisco Ortiz & Partidor & 9 días 2 pesos \\
\hline
\end{tabular}

Fuente: AGN, Reales Cedulas, Originales y duplicados, exp. 77, f.102. 
Tabla 6: Nombre y sueldo de los peones y capataz

\begin{tabular}{|c|c|c|c|c|c|}
\hline Nombres & Ocupación & Sueldo & Nombres & Ocupación & Sueldo \\
\hline $\begin{array}{l}\text { Joseph de } \\
\text { Casas }\end{array}$ & Capataz & 6 días 3 pesos & José Lorenzo & Peón & 9 días 1 peso \\
\hline Rafael Vargas & Peón & 9 días 1 peso & Pedro Nolasco & Peón & 9 días 1 peso \\
\hline $\begin{array}{l}\text { Miguel } \\
\text { Márquez }\end{array}$ & Peón & 9 días 1 peso & $\begin{array}{l}\text { Manuel } \\
\text { Bartolomé }\end{array}$ & Peón & 4 días 1 peso \\
\hline $\begin{array}{l}\text { Bartolomé } \\
\text { Morales }\end{array}$ & Peón & 9 días 1 peso & $\begin{array}{l}\text { Manuel José de } \\
\text { María }\end{array}$ & Peón & 4 días 1 peso \\
\hline $\begin{array}{l}\text { Marcelo } \\
\text { Palacios }\end{array}$ & Peón & 9 días 1 peso & Felix de Santiago & Peón & 4 días 1 peso \\
\hline José Parcia & Peón & 9 días 1 peso & $\begin{array}{l}\text { Cayetano } \\
\text { Francisco }\end{array}$ & Peón & 9 días 1 peso \\
\hline $\begin{array}{l}\text { Manuel } \\
\text { Córdova }\end{array}$ & Peón & 9 días 1 peso & Lugo Fernández & Peón & $3 / 4$ día o peso \\
\hline José Miranda & Peón & 9 días 1 peso & Pedro Fernández & Peón & 3/4 día o peso \\
\hline Antonio Ortiz & Peón & 9 días 1 peso & Martin Fernández & Peón & 5 días 1 peso \\
\hline $\begin{array}{l}\text { Manuel } \\
\text { Antonio }\end{array}$ & Peón & 9 días 1 peso & Thomas Días & Peón & 4 días 1 peso \\
\hline Diego Severino & Peón & 9 días o peso & Miguel López & Peón & $\begin{array}{c}3 \text { días o pe- } \\
\text { sos }\end{array}$ \\
\hline José Arturo & Peón & 9 días 1 peso & Antonio López & Peón & 4 días 1 peso \\
\hline José Costanzo & Peón & 9 días 1 peso & Francisco José & Peón & 4 días 1 peso \\
\hline José Guerrero & Peón & 2 días o pesos & José Tonqueras & Peón & 4 días 1 peso \\
\hline Juan Amaro & Peón & 5 días 1 peso & Juan Martin & Peón & 5 días 1 peso \\
\hline Pedro Morales & Peón & 4 días 1 peso & $\begin{array}{l}\text { Cristóbal } \\
\text { Caramillo }\end{array}$ & Peón & $\begin{array}{c}2 \text { días o pe- } \\
\text { sos }\end{array}$ \\
\hline José Miguel & Peón & 4 días 1 peso & & & \\
\hline
\end{tabular}

Fuente: AGN, Reales Cedulas, Originales y duplicados, exp.77, ff.102-103.

Tabla 7: Nombre y sueldo de los capataces

\begin{tabular}{|l|c|c|}
\hline \multicolumn{1}{|c|}{ Nombres } & Ocupación & Sueldo \\
\hline José Rincón & Capataz & 6 dias 3 pesos \\
\hline Pedro Montenegro & Capataz & 6 días 3 pesos \\
\hline Manuel José & Capataz & 6 días 2 pesos \\
\hline Diego Borja & Capataz & 6 días a 1 peso \\
\hline Juan Antonio Hernández & Capataz & 6 días 1 peso \\
\hline
\end{tabular}

Fuente: AGN, Reales Cedulas, Originales y duplicados, exp.77, f.103v. 
Tabla 8: Nombre y sueldo de los peones de excavación

\begin{tabular}{|c|c|c|c|c|c|}
\hline Nombres & Sueldo & Nombres & Sueldo & Nombres & Sueldo \\
\hline Nicolás Trujillo & 6 días 1 peso & Bartolomé Lázaro & 6 días 1 peso & Diego Osorio & 6 días 1 peso \\
\hline Manuel José & 6 días 1 peso & $\begin{array}{l}\text { Enrique } \\
\text { Hernández }\end{array}$ & 6 días 1 peso & $\begin{array}{l}\text { Pascual la } \\
\text { Cruz }\end{array}$ & 6 días o peso \\
\hline Juan Herrera & 6 días 1 peso & Juan Feliciano & 6 días 1 peso & $\begin{array}{l}\text { Alonso de la } \\
\text { Cruz }\end{array}$ & 6 días o peso \\
\hline Marcelo Antonio & 6 días 1 peso & Francisco Jiménez & 6 días 1 peso & Juan Luciano & 6 días 1 peso \\
\hline Antonio Pablo & 6 días 1 peso & Baltasar Rojas & 6 días 1 peso & Diego Juan & 6 días o peso \\
\hline Manuel Rincón & 6 días 1 peso & $\begin{array}{l}\text { Diego Martín } \\
\text { García }\end{array}$ & 6 días 1 peso & Jacinto José & 6 días o peso \\
\hline José Polinario & 6 días 1 peso & $\begin{array}{l}\text { Manuel Pascual } \\
\text { Alamo }\end{array}$ & 6 días 1 peso & $\begin{array}{l}\text { José Manuel } \\
\text { Eusebio }\end{array}$ & 6 días 1 peso \\
\hline José Ruiz García & 6 días 1 peso & Miguel Ruiz & 6 días 1 peso & $\begin{array}{l}\text { Pascual la } \\
\text { Cruz }\end{array}$ & 6 días 1 peso \\
\hline Feliz Cortina & 6 días 1 peso & Antonio Martin & 6 días 1 peso & Juan Reyes & 6 días 1 peso \\
\hline Diego Martín & 6 días 1 peso & Diego Martin & 6 días 1 peso & $\begin{array}{l}\text { Manuel Anto- } \\
\text { nio }\end{array}$ & 6 días 1 peso \\
\hline Feliz Antonio & 6 días 1 peso & Antonio Cruz & 6 días 1 peso & $\begin{array}{l}\text { Lorenzo Geró- } \\
\text { nimo }\end{array}$ & 6 días 1 peso \\
\hline Diego Martín & 6 días 1 peso & Manuel Antonio & 6 días 1 peso & Manuel José & 6 días 1 peso \\
\hline Rafael García & 6 días 1 peso & Manuel Cruz & 6 días 1 peso & $\begin{array}{l}\text { Mariano } \\
\text { Antonio }\end{array}$ & 6 días 1 peso \\
\hline Carlos Eusebio & 5 días 1 peso & Manuel Osorio & 6 días 1 peso & $\begin{array}{l}\text { Manuel Cruz } \\
\text { Soltero }\end{array}$ & 6 días o peso \\
\hline Diego Beltrán & 4 días 1 peso & Manuel Salvador & 6 días 1 peso & Juan Cortez & 6 días 1 peso \\
\hline José Casas & 6 días 1 peso & Francisco Ruiz & 6 días 1 peso & Pedro Martin & 6 días 1 peso \\
\hline $\begin{array}{l}\text { Laureano } \\
\text { Quintero }\end{array}$ & 6 días 1 peso & Diego Martín & 6 días 1 peso & José Murrieta & 6 días 1 peso \\
\hline Franco Luna & 6 días 1 peso & José Martín & 6 días 1 peso & $\begin{array}{l}\text { Andrés } \\
\text { Córdova }\end{array}$ & 6 días 1 peso \\
\hline José paulino & 6 días 1 peso & Pedro Hernández & 6 días 1 peso & $\begin{array}{l}\text { Manuel } \\
\text { Chinanteco }\end{array}$ & 6 días 1 peso \\
\hline Thomas Franco & 6 días 1 peso & Miguel Juárez & 6 días 1 peso & $\begin{array}{l}\text { Francisco } \\
\text { Martin }\end{array}$ & 6 días 1 peso \\
\hline Juan López & 3 días o peso & Franco Hipólito & 6 días 1 peso & Juan Miguel & 6 días o peso \\
\hline José Rodrigo & 6 días 1 peso & $\begin{array}{l}\text { Domingo } \\
\text { Hernández }\end{array}$ & 6 días 1 peso & José Diego & 6 días 1 peso \\
\hline $\begin{array}{l}\text { Francisco } \\
\text { Romero }\end{array}$ & 6 días 1 peso & Antonio Espirita & 6 días 1 peso & José Ramos & 6 días 1 peso \\
\hline Dionisio Rodrigo & 6 días 1 peso & Juan Mariano & 6 días 1 peso & $\begin{array}{l}\text { Santiago } \\
\text { Guzmán }\end{array}$ & 6 días 1 peso \\
\hline Juan Rosas & 6 días 1 peso & Juan Rafael & 6 días 1 peso & Juan Antonio & 6 días 1 peso \\
\hline Diego o Martínez & 6 días 1 peso & Manuel Salvador & 6 días 1 peso & Diego Ami & 6 días 1 peso \\
\hline $\begin{array}{l}\text { José Franco } \\
\text { Peón Isco }\end{array}$ & 6 días 1 peso & Juan Francisco & 6 días 1 peso & Manuel Ramos & días 1 peso \\
\hline Diego Olivares & 6 días 1 peso & Pedro Hernández & 6 días 1 peso & Nicolás López & 6 días 1 peso \\
\hline Juan Antonio & 6 días 1 peso & Juan Martín & 6 días 1 peso & $\begin{array}{l}\text { Bartolomé } \\
\text { Gabriel }\end{array}$ & 6 días 1 peso \\
\hline
\end{tabular}




\begin{tabular}{|c|c|c|c|c|c|}
\hline Manuel Arauz & 6 días 1 peso & $\begin{array}{l}\text { Sebastián } \\
\text { Hernández }\end{array}$ & 6 días 1 peso & $\begin{array}{l}\text { Manuel } \\
\text { Ignacio }\end{array}$ & 6 días 1 peso \\
\hline $\begin{array}{l}\text { José Francisco } \\
\text { Velasco }\end{array}$ & 6 días 1 peso & $\begin{array}{l}\text { Pedro Hernández } \\
\text { de María }\end{array}$ & 6 días 1 peso & Francisco Juan & 6 días 1 peso \\
\hline Manuel José & 6 días o pesos & Manuel Diego & 6 días 1 peso & José Cristóbal & 6 días 1 peso \\
\hline Julián Báez & 6 días 1 peso & Miguel Thomas & 6 días 1 peso & $\begin{array}{l}\text { Bernardo } \\
\text { Cristóbal }\end{array}$ & 6 días 1 peso \\
\hline Salvador Rendón & 6 días 1 peso & Juan Lucas & 6 días 1 peso & $\begin{array}{l}\text { Sebastián } \\
\text { Fabián }\end{array}$ & 6 días 1 peso \\
\hline Cayetano Amori & 6 días 1 peso & Francisco Cornelio & 6 días 1 peso & $\begin{array}{l}\text { Ambrosio } \\
\text { Gerónimo }\end{array}$ & 6 días 1 peso \\
\hline Juan Domínguez & 6 días o pesos & Juan Antonio & 6 días 1 peso & José Ramos & 6 días 1 peso \\
\hline Manuel Córdova & 6 días o pesos & Francisco Alonso & 6 días 1 peso & Juan Martin & 6 días 1 peso \\
\hline Patricio Muñoz & 6 días o pesos & Antonio Alonso & 6 días 1 peso & Miguel Lucas & 6 días 1 peso \\
\hline Pascual José & 6 días 1 peso & Miguel Antonio & 6 días 1 peso & $\begin{array}{l}\text { Thomas } \\
\text { Gerónimo }\end{array}$ & 6 días 1 peso \\
\hline Francisco Vargas & 6 días 1 peso & Baltasar Calderón & 6 días 1 peso & $\begin{array}{l}\text { Gerónimo } \\
\text { Juan }\end{array}$ & 6 días 1 peso \\
\hline José Toro & 5 días o pesos & Agustín Nicolás & 6 días 1 peso & $\begin{array}{l}\text { Manuel } \\
\text { Antonio }\end{array}$ & 6 días 1 peso \\
\hline $\begin{array}{l}\text { Francisco } \\
\text { Callejas }\end{array}$ & 6 días o pesos & Juan Matías & 6 días 1 peso & $\begin{array}{l}\text { Francisco } \\
\text { Antonio }\end{array}$ & 6 días 1 peso \\
\hline Marostro Martin & 6 días o pesos & $\begin{array}{l}\text { Manuel Salvador } \\
\text { de Dolores }\end{array}$ & 6 días 1 peso & $\begin{array}{l}\text { Francisco } \\
\text { Ventura }\end{array}$ & 6 días 1 peso \\
\hline Juan Franco & 6 días 1 peso & Manuel Cayetano & 6 días 1 peso & Diego Ventura & 6 días 1 peso \\
\hline Rafael Romero & 6 días 1 peso & Juan Reyes & 6 días 1 peso & $\begin{array}{l}\text { Andrés } \\
\text { Velazco }\end{array}$ & 6 días 1 peso \\
\hline Eusebio Fuentes & 6 días 1 peso & Luis Francisco & 6 días o peso & $\begin{array}{l}\text { Manuel Salva- } \\
\text { dor }\end{array}$ & 6 días 1 peso \\
\hline José Bernandino & 1 día o pesos & Diego Martin & 6 días o peso & $\begin{array}{l}\text { Marestro la } \\
\text { Cruz }\end{array}$ & 6 días 1 peso \\
\hline Rafael Piqueindi & 6 días 1 peso & Juan Pascual & 6 días o peso & Miguel Pérez & 6 días 1 peso \\
\hline $\begin{array}{l}\text { Francisco } \\
\text { Castelán }\end{array}$ & 6 días 1 peso & Juan Antonio & 6 días o peso & Juan Santos & 6 días 1 peso \\
\hline José Prarrillo & 5 días o pesos & Gerónimo Bapta & 6 días o peso & José Manuel & 6 días 1 peso \\
\hline José Zavaleta & 6 días 1 peso & Nicolás Gerónimo & 6 días o peso & $\begin{array}{l}\text { Manuel de la } \\
\text { Cruz }\end{array}$ & 6 días 1 peso \\
\hline Leandro Antonio & 6 días o pesos & Juan Agustín & 6 días o peso & $\begin{array}{l}\text { Pascual } \\
\text { Guzmán }\end{array}$ & 6 días 1 peso \\
\hline Antonio Alcaide & 6 días o pesos & Juan Feliciano & 6 días o peso & José Calisto & 6 días 1 peso \\
\hline Domingo María & 6 días 1 peso & Manuel Ami & 6 días o peso & Martin Juárez & 6 días 1 peso \\
\hline José Tenorio & 6 días 1 peso & Marcelo Angelina & 6 días o peso & Alonso Marcos & 6 días 1 peso \\
\hline Juan Aparicio & 6 días 1 peso & Andrés Franco & 6 días o peso & $\begin{array}{l}\text { Francisco } \\
\text { Lorenzo }\end{array}$ & 6 días 1 peso \\
\hline $\begin{array}{l}\text { Gregorio } \\
\text { Ausencio }\end{array}$ & 6 días o pesos & Salvador Antonio & 6 días 1 peso & Manuel Rosa & 6 días 1 peso \\
\hline Miguel Castelán & 6 días o pesos & Manuel Salvador & 6 días 1 peso & Antonio García & 6 días 1 peso \\
\hline Manuel Gervasio & 6 días o pesos & Juan Antonio & 6 días 1 peso & Antonio Pérez & 6 días 1 peso \\
\hline Paul Mariano & 6 días 1 peso & Diego Melchor & 6 días 1 peso & José Perdomo & 6 días 1 peso \\
\hline
\end{tabular}




\begin{tabular}{|c|c|c|c|c|c|}
\hline Diego José & 6 días peso & Juan Domingo & 6 días 1 peso & Diego Antonio & 6 días 1 peso \\
\hline José Ángel & 6 días 1 peso & Manuel Bartolo & 6 días 1 peso & $\begin{array}{l}\text { Pascual } \\
\text { Alirabien }\end{array}$ & 6 días 1 peso \\
\hline Alan Salvador & 6 días 1 peso & Francisco Thomas & 6 días 1 peso & Pedro Ramírez & 6 días 1 peso \\
\hline Juan Bapla & 6 días 1 peso & Mariano Ami & 6 días 1 peso & Lorenzo Juan & 6 días 1 peso \\
\hline $\begin{array}{l}\text { Salvador } \\
\text { Hernández }\end{array}$ & 6 días 1 peso & Nicolás Juan & 6 días 1 peso & $\begin{array}{l}\text { Antonio } \\
\text { Trinidad }\end{array}$ & 6 días 1 peso \\
\hline $\begin{array}{l}\text { Juan Bapla de } \\
\text { María }\end{array}$ & 6 días 1 peso & Gabriel Sánchez & 6 días 1 peso & $\begin{array}{l}\text { Marcos } \\
\text { Francisco }\end{array}$ & 6 días 1 peso \\
\hline Juan Marcelo & 6 días 1 peso & Marcos García & 6 días 1 peso & José Santos & 6 días 1 peso \\
\hline Manuel Salvador & 6 días 1 peso & Manuel La Cruz & 6 días 1 peso & Manuel Cortez & 6 días 1 peso \\
\hline Antonio Martin & 6 días 1 peso & Manuel Samuel & 6 días o peso & $\begin{array}{l}\text { Thomas } \\
\text { Gerónimo }\end{array}$ & 6 días 1 peso \\
\hline Pedro Antonio & 6 días 1 peso & Manuel Isidro & 6 días 1 peso & $\begin{array}{l}\text { Manuel } \\
\text { Salvador }\end{array}$ & 6 días 1 peso \\
\hline Luis Hernández & 6 días 1 peso & Andrés Hernández & 6 días 1 peso & $\begin{array}{l}\text { Bartolomé de } \\
\text { Domínguez }\end{array}$ & 6 días 1 peso \\
\hline Sebastián Fabián & 6 días 1 peso & Melchor Antonio & 6 días 1 peso & Lisandro Brión & 6 días 1 peso \\
\hline Diego Santiago & 2 días o pesos & Gabriel Juan & 6 días 1 peso & $\begin{array}{l}\text { Lorenzo } \\
\text { Pimentel }\end{array}$ & 6 días 1 peso \\
\hline Diego Nicolás & 6 días 1 peso & Bernardo Martin & 6 días 1 peso & Pedro de José & 6 días o peso \\
\hline $\begin{array}{l}\text { Juan Bapla de } \\
\text { María }\end{array}$ & 6 días 1 peso & Gaspar Franco & 6 días 1 peso & $\begin{array}{l}\text { Miguel } \\
\text { Antonio }\end{array}$ & 6 días o peso \\
\hline Miguel Juárez & 6 días 1 peso & Domingo Pascual & 6 días 1 peso & $\begin{array}{l}\text { Thomas la } \\
\text { Cruz }\end{array}$ & 6 días o peso \\
\hline Francisco Martin & 6 días 1 peso & Manuel Romos & 6 días 1 peso & $\begin{array}{l}\text { Manuel } \\
\text { Salvador }\end{array}$ & 6 días o peso \\
\hline Juan Sánchez & 6 días 1 peso & Juan Severiano & 6 días 1 peso & $\begin{array}{l}\text { Domingo } \\
\text { Antonio }\end{array}$ & 6 días o peso \\
\hline Manuel Salvador & 6 días 1 peso & Antonio Palacios & 6 días 1 peso & $\begin{array}{l}\text { Moisés Salva- } \\
\text { dor Martin }\end{array}$ & 6 días o peso \\
\hline Luis Hernández & 6 días 1 peso & Benito Juan & 6 días 1 peso & Mateo Pedraza & 6 días o peso \\
\hline Bartolomé Pérez & 6 días 1 peso & Juan Martín & 6 días 1 peso & $\begin{array}{l}\text { Bartolomé } \\
\text { Francisco }\end{array}$ & 6 días o peso \\
\hline Franco Amaro & 6 días 1 peso & Luis José & 6 días 1 peso & José Francisco & 6 días o peso \\
\hline Miguel Antonio & 6 días 1 peso & Manuel Salvador & 6 días 1 peso & Luis Toribio & 6 días o peso \\
\hline Rafael Díaz & 6 días 1 peso & Miguel Francisco & 6 días 1 peso & Franco Miguel & 6 días 1 peso \\
\hline Bartolomé Lujan & 6 días 1 peso & José Antonio & 6 días 1 peso & $\begin{array}{l}\text { Luis Miguel } \\
\text { Antonio }\end{array}$ & 6 días 1 peso \\
\hline Nicolás Leandro & 6 días 1 peso & Juan Martín & 6 días 1 peso & Pascual José & 6 días 1 peso \\
\hline $\begin{array}{l}\text { Bernardo } \\
\text { Hernández }\end{array}$ & 6 días 1 peso & Juan Zamora & 6 días 1 peso & $\begin{array}{l}\text { Juan Antonio } \\
\text { de María }\end{array}$ & 6 días 1 peso \\
\hline Luis Asencio & 6 días 1 peso & Juan de la Cruz & 6 días 1 peso & Luis Ami & 6 días 1 peso \\
\hline Manuel Antonio & 6 días 1 peso & Miguel Gerónimo & 6 días 1 peso & Diego Toribio & 6 días 1 peso \\
\hline Pedro González & 6 días 1 peso & $\begin{array}{l}\text { Salvador } \\
\text { Hernández }\end{array}$ & 6 días 1 peso & $\begin{array}{l}\text { Pascual la } \\
\text { Cruz }\end{array}$ & 6 días 1 peso \\
\hline Luis Hernández & 6 días 1 peso & Salvador Ami & 6 días 1 peso & $\begin{array}{l}\text { Nicolás } \\
\text { Méndez }\end{array}$ & 6 días 1 peso \\
\hline
\end{tabular}




\begin{tabular}{|c|c|c|c|c|c|}
\hline Juan Diego & 6 días 1 peso & Domingo Ramos & 6 días 1 peso & Diego Martin & 6 días 1 peso \\
\hline Juan Baltasar & 6 días 1 peso & Gabriel Mendoza & 6 días 1 peso & $\begin{array}{l}\text { Marcelo } \\
\text { Ramos }\end{array}$ & 6 días 1 peso \\
\hline Diego Hernández & 6 días 1 peso & Juan Pablo & 6 días 1 peso & Luis Martin & 6 días 1 peso \\
\hline Juan Thomas & 6 días 1 peso & Domingo Melchor & 6 días 1 peso & $\begin{array}{l}\text { Mariano } \\
\text { Antonio }\end{array}$ & 6 días 1 peso \\
\hline José Ángel & 6 días 1 peso & Daniel Melchor & 6 días 1 peso & $\begin{array}{l}\text { Juan Martin } \\
\text { Vázquez }\end{array}$ & 6 días 1 peso \\
\hline Manuel Andrés & 6 días 1 peso & Mariano José & 6 días 1 peso & Antonio Pedro & 6 días 1 peso \\
\hline Carlos Higueras & 6 días 1 peso & $\begin{array}{l}\text { Antonio } \\
\text { Hernández }\end{array}$ & 6 días 1 peso & Pablo Ruiz & 6 días 1 peso \\
\hline Bartolo Juárez & 6 días 1 peso & Juan Francisco & 6 días 1 peso & Miguel Barrios & 4 días 1 peso \\
\hline Manuel Martin & 6 días 1 peso & Juan Domingo & 6 días 1 peso & Juan Antonio & 6 días 1 peso \\
\hline Manuel Salvador & 6 días 1 peso & Pascual Alonso & 6 días 1 peso & Salvador Juan & 6 días 1 peso \\
\hline Manuel Pascual & 6 días 1 peso & Marcos Bernabé & 6 días 1 peso & Juan Santiago & 6 días 1 peso \\
\hline Diego Nicolás & 6 días 1 peso & Lucas Pérez & 6 días 1 peso & $\begin{array}{l}\text { Antonio } \\
\text { Ventura }\end{array}$ & 6 días 1 peso \\
\hline Miguel Feliciano & 6 días 1 peso & Diego Martín & 6 días 1 peso & José García & 6 días 1 peso \\
\hline Miguel Francisco & 6 días 1 peso & $\begin{array}{l}\text { Thomas } \\
\text { Hernández }\end{array}$ & 6 días 1 peso & Juan Agustín & 6 días 1 peso \\
\hline Juan Andrés & 6 días 1 peso & Marco Juárez & 6 días 1 peso & Juan Ruiz & 6 días 1 peso \\
\hline $\begin{array}{l}\text { Thomas } \\
\text { Gerónimo }\end{array}$ & 6 días 1 peso & Francisco García & 6 días 1 peso & $\begin{array}{l}\text { Francisco } \\
\text { Ramos }\end{array}$ & 6 días 1 peso \\
\hline Daniel de la Cruz & 6 días 1 peso & Pedro Juárez & 6 días 1 peso & Diego Lázaro & 2 días o peso \\
\hline Luis de la Cruz & 6 días 1 peso & Diego Alonso & 6 días 1 peso & Miguel Pedro & 6 días 1 peso \\
\hline Diego Hernández & 6 días 1 peso & Diego Baltasar & 6 días 1 peso & $\begin{array}{l}\text { Juan } \\
\text { Bartolomé }\end{array}$ & 6 días 1 peso \\
\hline Martin Luis & 6 días 1 peso & Franco Luna & 6 días 1 peso & Pascual Bailon & 6 días 1 peso \\
\hline $\begin{array}{l}\text { Nicolás } \\
\text { Gerónimo }\end{array}$ & 6 días 1 peso & Miguel Hernández & 6 días 1 peso & $\begin{array}{l}\text { Miguel } \\
\text { Aparicio }\end{array}$ & 6 días 1 peso \\
\hline Domingo Pérez & 6 días 1 peso & Diego Cruz & 6 días 1 peso & Juan Benito & 6 días 1 peso \\
\hline Juan Baltasar & 6 días 1 peso & Pedro Santiago & 6 días 1 peso & Antonio Pedro & 6 días 1 peso \\
\hline Cristóbal Pérez & 6 días 1 peso & Manuel Salvador & 6 días 1 peso & $\begin{array}{l}\text { Francisco } \\
\text { Alberto }\end{array}$ & 6 días 1 peso \\
\hline Miguel Santos & 6 días 1 peso & Pedro Rojas & 6 días 1 peso & $\begin{array}{l}\text { Diego } \\
\text { Francisco }\end{array}$ & 6 días 1 peso \\
\hline Juan Pascual & 6 días 1 peso & Luis Pérez & 6 días 1 peso & $\begin{array}{l}\text { Juan de la } \\
\text { Cruz }\end{array}$ & 6 días 1 peso \\
\hline José Velasco & 6 días 1 peso & $\begin{array}{l}\text { Domingo Hernán- } \\
\text { dez }\end{array}$ & 6 días 1 peso & José Sijiriano & 6 días 1 peso \\
\hline $\begin{array}{l}\text { Francisco } \\
\text { Pascual }\end{array}$ & 6 días 1 peso & Juan Lucas & 6 días 1 peso & Lucas Antonio & 6 días 1 peso \\
\hline José Martín & 6 días 1 peso & Manuel Manestros & 6 días 1 peso & Pedro Nicolás & 6 días o peso \\
\hline $\begin{array}{l}\text { Manuel de la } \\
\text { Cruz }\end{array}$ & 6 días 1 peso & Juan Osorio & 6 días 1 peso & $\begin{array}{l}\text { Francisco } \\
\text { Javier }\end{array}$ & 5 días o peso \\
\hline Gaspar Pérez & 6 días 1 peso & Antón la cruz & 6 días 1 peso & $\begin{array}{l}\text { Daniel } \\
\text { Fernando }\end{array}$ & 6 días 1 peso \\
\hline José Martin & 6 días 1 peso & Berristo la Cruz & 6 días 1 peso & $\begin{array}{l}\text { Ami de la } \\
\text { Torre }\end{array}$ & 6 días 1 peso \\
\hline
\end{tabular}




\begin{tabular}{|c|c|c|c|c|c|}
\hline Manuel Salvador & 6 días 1 peso & Martin Pérez & 6 días 1 peso & Franco la Cruz & 6 días 1 peso \\
\hline Juan Bapla & 6 días 1 peso & Luis Munguía & 6 días 1 peso & $\begin{array}{l}\text { Julián } \\
\text { Santiago }\end{array}$ & 6 días 1 peso \\
\hline $\begin{array}{l}\text { Antonio } \\
\text { Francisco }\end{array}$ & 6 días 1 peso & Juan Cabrera & 6 días 1 peso & Manuel Jose & 6 días 1 peso \\
\hline José Tiburcio & 6 días 1 peso & Santiago Ramón & 6 días 1 peso & $\begin{array}{l}\text { Manuel } \\
\text { Aparicio }\end{array}$ & 6 días 1 peso \\
\hline Gabriel Morales & 6 días 1 peso & Gabriel Juan & 6 días 1 peso & $\begin{array}{l}\text { Manuel } \\
\text { Salvador }\end{array}$ & 6 días 1 peso \\
\hline $\begin{array}{l}\text { Pedro Hernández } \\
\text { García }\end{array}$ & 6 días 1 peso & Juan Salvador & 6 días 1 peso & $\begin{array}{l}\text { Thomas } \\
\text { Francisco }\end{array}$ & 6 días 1 peso \\
\hline Juan Baltasar & 6 días 1 peso & Marcos Huérfano & 6 días 1 peso & $\begin{array}{l}\text { Miguel } \\
\text { Aparicio }\end{array}$ & 6 días 1 peso \\
\hline Pedro Ami & 6 días 1 peso & Juan Cristóbal & 6 días 1 peso & Salvador Cruz & 6 días 1 peso \\
\hline Juan Hernández & 6 días 1 peso & Salvador Miguel & 6 días 1 peso & Lucas Miguel & 6 días 1 peso \\
\hline $\begin{array}{l}\text { Francisco } \\
\text { Atanasio }\end{array}$ & 6 días 1 peso & $\begin{array}{l}\text { Juan Martín de } \\
\text { Aguirre }\end{array}$ & 6 días 1 peso & $\begin{array}{l}\text { Thomas } \\
\text { Gerónimo }\end{array}$ & 6 días 1 peso \\
\hline Diego Pérez & 6 días 1 peso & Juan Pedro & 6 días 1 peso & $\begin{array}{l}\text { Salvador Cruz } \\
\text { de Ana }\end{array}$ & 6 días 1 peso \\
\hline Manuel Salvador & 6 días 1 peso & Marcelo Admi & 6 días o peso & $\begin{array}{l}\text { Miguel Fran- } \\
\text { cisco Salvador }\end{array}$ & 6 días 1 peso \\
\hline Juan Mateo & 6 días 1 peso & Miguel Córdova & 6 días o peso & $\begin{array}{l}\text { Martin } \\
\text { Bernabé }\end{array}$ & 6 días 1 peso \\
\hline José Tomas & 6 días 1 peso & Lorenzo Santos & 6 días o peso & & \\
\hline
\end{tabular}

Fuente: AGN, Reales Cedulas, Originales y duplicados, exp.77, ff.103-109.

Tabla 9: Nombre y sueldo de los carreteros

\begin{tabular}{|l|l|l|l|}
\hline \multicolumn{1}{|c|}{ Nombres } & Sueldo & \multicolumn{1}{c|}{ Nombres } & \multicolumn{1}{c|}{ Sueldo } \\
\hline Francisco Ortiz & 6 días 3 pesos & Pedro Ruiz García & 6 días 1 peso \\
\hline José Fonseca & 6 días 1 peso & José Córdova & 6 días 1 peso \\
\hline Antonio García & 6 días 1 peso & José Trinidad & 6 días 1 peso \\
\hline José Antonio & 6 días 1 peso & Juan Bapta & 6 días 1 peso \\
\hline Juan Soto & 6 días 1 peso & Pascual Antonio & 6 días 1 peso \\
\hline Juan Pablo & 6 días 1 peso & Simón Santos & 6 días 1 peso \\
\hline Manuel Santos & 6 días 1 peso & José Mariano Fernán- & 6 días 1 peso \\
\hline Juan Lorenzo & 6 días 1 peso & Pedro González & 6 días 1 peso \\
\hline Sebastián Pérez & 6 días 1 peso & José Manuel López & 6 días 1 peso \\
\hline Cayetano Torres & 6 días 1 peso & Isidro Casas & 6 días 1 peso \\
\hline Antonio Ruiz & 6 días 1 peso & Francisco Antonio & 6 días 1 peso \\
\hline Antonio Oyo & 6 días 1 peso & & \\
\hline
\end{tabular}

Fuente: AGN, Reales Cedulas, Originales y duplicados, exp.77, ff.109-110. 
Tabla 10: Nombre y sueldo del mozo de mula

\begin{tabular}{|l|c|c|}
\hline \multicolumn{1}{|c|}{ Nombre } & Ocupación & Sueldo \\
\hline Maestro Miguel & Mozo de mula & 6 días 1 peso
\end{tabular}

Fuente: AGN, Reales Cedulas, Originales y duplicados, exp.77, f.110.

Tabla 11: Nombre y sueldo de los conductores de piedra

\begin{tabular}{|l|}
\multicolumn{1}{|c}{ Nombres } \\
\hline José Mariano \\
\hline Andrés Cromos \\
\hline Juan Márquez \\
\hline Miguel Santamaría \\
\hline Miguel Neria \\
\hline Antonio Mota \\
\hline
\end{tabular}

\section{Ocupación}

Conductor de Piedra

Conductor de Piedra

Conductor de Piedra

Conductor de Piedra

Conductor de Piedra

Conductor de Piedra

\section{Sueldo}

6.52 cargas 3 pesos

6.42 cargas 2 pesos

$6.69^{1 / 2}$ cargas 4 pesos

2.23 cargas 1 pesos

2.58 cargas 3 pesos

6.46 cargas 2 pesos

Fuente: AGN, Reales Cedulas, Originales y duplicados, exp.77, f.110.

Tabla 12: Sueldos de los operarios de maestranza

\begin{tabular}{|l|l|} 
& Cargo \\
\hline Sargentos & \\
\hline Cabos \\
\hline Obreros \\
\hline Aprendiz
\end{tabular}

\section{Sueldo}

53 p. al mes

42 p. al mes

$30 \mathrm{p}$. al mes

$15 \mathrm{p}$. al mes

Fuente: AGN, Indiferente de guerra, vol.276a, f.18. 
Tabla 13: Relación de las herramientas para 8 carpinteros y un tornero de maestranza

Herramienta

\begin{tabular}{|l|}
\hline Acha de dos manos \\
\hline Dichas de una mano \\
\hline Azuelas de manos, las dos reservas y una para tornero \\
\hline Escoplos de dos tamaños \\
\hline ¿Tornones? de ídem. \\
\hline Barrenas de ídem. \\
\hline Garlopas y garlopines \\
\hline Cepillos \\
\hline Martillos de oreja \\
\hline Compases, uno grande \\
\hline Cartabones y esquadras \\
\hline Pares de codales \\
\hline Barletes \\
\hline Cubias de todas clases \\
\hline Sierras, braceras medianas de manos y serruchos \\
\hline Limas y limazones de todas las clases \\
\hline Cuchillas de pulir \\
\hline Trabajadores grandes y chicos \\
\hline Mazos de mano y tres de enhierrar \\
\hline Gramiles \\
\hline Salta reglas \\
\hline Burriquetes \\
\hline Bancos de prensa \\
\hline Tormones de pie de cabra, quadrados y de boca \\
\hline Redonda para tonero, cubias grandes y chicas \\
\hline Escoplos triángulos y regulares \\
\hline Campas curbo \\
\hline Barra de hierro \\
\hline Torno de rueda, y de barra otro \\
\hline Piedras de amolar \\
\hline Dichas de sentar filo \\
\hline \\
\hline
\end{tabular}

$\mathbf{N}^{\circ}$ de piezas

\begin{tabular}{|c|}
\hline 6 \\
\hline 3 \\
\hline 10 \\
\hline 1 \\
\hline 12 \\
\hline 4 \\
\hline 4 \\
\hline 2 \\
\hline 4 \\
\hline 4 \\
\hline 3 \\
\hline 2 \\
\hline 8 \\
\hline 12 \\
\hline 12 \\
\hline 2 \\
\hline 2 \\
\hline 9 \\
\hline 4 \\
\hline 4 \\
\hline 2 \\
\hline 4 \\
\hline 2 \\
\hline 4 \\
\hline 1 \\
\hline 1 \\
\hline
\end{tabular}

Fuente: AGN, Indiferente de guerra, vol.276a, f.18. 


\section{Bibliografía:}

\section{Fuentes primarias:}

Archivo General de Indias (AGN), Indiferente General, Lima.

Archivo General de la Nación, México (AGN), Caminos y Calzadas, Indiferente de Guerra, Obras Públicas, Reales Cedulas Originales y duplicados, Registros de finanzas, depósito y obligaciones.

\section{Fuentes secundarias:}

Alberro, Solange, "Bebidas alcohólicas y sociedad colonial en México: un intento de interpretación" en Revista Mexicana de Sociología n. ${ }^{\circ}$ 2, México D. F., El Colegio de México, 1989, pp.349-359.

Almonte, Juan, Memoria de Ministro de Guerra y Marina, presentada a las cámaras del Congreso General Mexicano, en Enero de 1840, México D. F., Oficina el Águila, 1840 .

Archer, Christon, El ejército en el México Borbónico: 1760-181o, México D. F., FCE, 1983.

Archer, Christon, "The role of the Military in Colonial Latin America" en The History Teacher n. $^{\circ}$ 3, California, The Society for History Education, Inc., 1981, pp.413-421.

Arias, Luz Maria, "Building Fiscal Capacity in Colonial Mexico: From Fragmentation to Centralization", in The Journal of Economic History n. ${ }^{\circ}$, Cambridge, Cambridge University Press, 2013, pp.662-693.

Baeza, Ascensión, "Fundición de Artillería en Nueva España: Proyectos Fallidos, la alternativa de Sevilla (1722-1794)", en María Luisa Laviana (coord.), Estudios sobre América; Siglos XVI-XX, vol.1, Sevilla, Asociación Española de Americanistas, 2005, pp. 879-903

Calderón, José Antonio, Historia de las fortificaciones en Nueva España, Madrid EEHA/CISC/Gobierno del Estado de Veracruz, 1984.

Challú, Amilcar, "Grain markets, free trade and the Bourbon reforms: The Real Pragmática of 1765 in New Spain", in Colonial Latin American Review n. ${ }^{\circ}$, Austin, Texas University Press, 2013, pp.400-421.

Cipolla, Carlo, Las Maquinas del tiempo y de la Guerra: Estudio de la génesis del capitalismo, Barcelona, Editorial Crítica, 1999.

Delgado, Ana Laura, Cien Viajeros en Veracruz: crónicas y relatos, tomo II, Xalapa, Gobierno del Estado de Veracruz, 1992.

Fuente, María de la, El arte militar en la Nueva España, 1762-1808, México D. F., tesis para obtener el grado de Doctor en Historia, UNAM, 2005. 
García de León, Antonio, Tierra adentro, mar en fuera. El puerto de Veracruz y su litoral a sotavento. 1519-1821, México D.F., FCE/Secretaria de Educación del Estado de Veracruz/Universidad Veracruzana, 2011.

Gerhard, Peter, Geografía histórica de la Nueva España. 1519-1821, México D. F., Instituto de Investigaciones Históricas, Universidad Nacional Autónoma de México, 1986.

Gómez, Carmen, El sistema defensivo americano. Siglo XVIII, Madrid, MAPFRE, 1992.

Gómez, Carmen, "El problema logístico y la operatividad de la artillería en América" en Militaría. Revista de Historia militar n. ${ }^{\circ} 10$, Madrid, Universidad Complutense de Madrid, 1997, pp.43-55.

Gutiérrez, Ramón, Fortificaciones en Iberoamérica, Madrid, Fundación Iberdrola/Ediciones El Viso, 2005.

Jörgensen, Christen et al, Técnicas Bélicas del mundo moderno, 150o-1763. Equipamiento, técnicas y tácticas de combate, Madrid, Ed. Libsa, 2007.

Martínez, Enrique et al, Ilustración, ciencia y técnica en el siglo XVIII español, Valencia, Universitat de Valencia, 2008.

Martiré, Eduardo, "La militarización de la monarquía borbónica. (¿Una monarquía militar?)", en Feliciano Barrios (coord.), El gobierno de un mundo: virreinatos y audiencias en la América Hispana, Cuenca, Ediciones de la Universidad de CastillaLa Mancha, 2004, pp.447-488.

Miño, Manuel, La protoindustria colonial en Hispanoamérica, México D. F., El Colegio de México/Fideicomiso Historia de las Américas/FCE, 1993.

Muñoz, Francisco et Blaisot, Benjamin, "L’influence de Vauban en Amérique Latine", en Thierry Martin et Michèle Virol (coord.), Vauban, architecte de la modernité?, Paris, Presses universitaires de Franche-Comté, 2008, pp.195-222.

Ramírez, David, Testimonio para una Historia de Perote, Xalapa, Editorial del Gobierno del Estado de Veracruz, 1973.

Rodríguez, Vicente, El fiscal de Real Hacienda en Nueva España: Don Ramón de Posada y Soto, 1781-1793, Oviedo, Universidad de Oviedo, 1985.

Romano, Ruggiero, "El trabajo compulsivo y trabajo libre en Nueva España (siglos XVIXVIII)” en Ángel Vaca (ed.), El trabajo en la historia, Salamanca, Ediciones de la Universidad de Salamanca, 1996, pp.199-210.

Sanchez, Miguel, El castillo de San Carlos de Perote, México D. F., Ed. Citlaltepetl, 1971.

Sanz, Sara Elizabeth, Fortalezas históricas de Veracruz, México D. F., Secretaría de Educación/ Gobierno del Estado de Vearcruz-Llave, 2010.

Siemens, Alfred, "El sur de Veracruz a finales del siglo XVIII. Un análisis de la relación de Corral", en Historia Mexicana n. ${ }^{\circ}$. México D. F., El Colegio de México, 1976, pp.264-324. 
Solano Sergio, Paolo, "Sistema de defensa, artesanado y sociedad en el Nuevo Reino de Granada. El caso de Cartagena de Indias, 1750-1810”, en Memorias vol.10, n. ${ }^{\circ} 19$, Barranquilla, Universidad del Norte, 2013, pp.92-139.

Solano, Sergio Paolo y Flórez, Roicer, "Artilleros pardos y morenos artistas: artesanos, raza, milicias y reconocimiento social en el Nuevo Reino de Granada, 1770-1812”, en Historia Critica n. ${ }^{\circ}$ 48, Bogotá, Universidad de los Andes, 2012, pp.11-37.

Zavala, Silvio, El servicio personal de los indios en la Nueva España, t.VII, Mexico D. F., El Colegio de México/El Colegio Nacional, 1995.

Zavala, Silvio, Los esclavos indios en Nueva España, México D. F., El Colegio Nacional, 1994.

Zavala, Silvio, Fuentes para la Historia del trabajo en la Nueva España, vol.viII, México D. F., Centro de Estudios Historicos del Movimiento Obrero Méxicano, 1980.

Zavala, Silvio, "La evolución del régimen de trabajo" en Ensayos sobre la colonización española en América, Buenos Aires, Emecé, 1944, pp.123-134. 